\title{
A spectral method for retrieving cloud optical thickness and effective radius from surface-based transmittance measurements
}

\author{
P. J. McBride ${ }^{1,2}$, K. S. Schmidt ${ }^{1}$, P. Pilewskie ${ }^{1,2}$, A. S. Kittelman ${ }^{2}$, and D. E. Wolfe ${ }^{3}$ \\ ${ }^{1}$ Laboratory for Atmospheric and Space Physics, University of Colorado, Campus Box 392, Boulder, \\ Colorado 80309-0392, USA \\ ${ }^{2}$ Department of Atmospheric and Oceanic Sciences, University of Colorado, Campus Box 311, Boulder, \\ CO 80309-0311, USA \\ ${ }^{3}$ NOAA Earth Systems Research Laboratory, Physical Science Division, Weather and Climate Physics Branch, 325 \\ Broadway, Boulder, CO 80305, USA
}

Received: 6 October 2010 - Published in Atmos. Chem. Phys. Discuss.: 17 January 2011

Revised: 7 June 2011 - Accepted: 7 July 2011 - Published: 25 July 2011

\begin{abstract}
We introduce a new spectral method for the retrieval of optical thickness and effective radius from cloud transmittance that relies on the spectral slope of the normalized transmittance between $1565 \mathrm{~nm}$ and $1634 \mathrm{~nm}$, and on cloud transmittance at a visible wavelength. The standard dual-wavelength technique, which is traditionally used in reflectance-based retrievals, is ill-suited for transmittance because it lacks sensitivity to effective radius, especially for optically thin clouds. Using the spectral slope rather than the transmittance itself enhances the sensitivity of transmittance observations with respect to the effective radius. This is demonstrated by applying it to the moderate spectral resolution observations from the Solar Spectral Flux Radiometer (SSFR) and Shortwave Spectroradiometer (SWS), and by examining the retrieval uncertainties of the standard and the spectral method for data from the DOE ARM Southern Great Plains (SGP) site and a NOAA ship cruise (ICEALOT). The liquid water path (LWP) is derived from the retrieved optical thickness and effective radius, based on two different assumptions about the cloud vertical profile, and compared to the simultaneous observations from a microwave radiometer. Optical thickness and effective radius is also compared to MODIS retrievals. In general, the effective radius uncertainties were much larger for the standard retrieval than for the spectral retrieval, particularly for thin clouds. When defining $2 \mu \mathrm{m}$ as upper limit for the tolerable uncertainty of the effective radius, the standard method returned only very few valid retrievals for clouds with an optical thickness below 25. For the analyzed ICEALOT data (mean optical thickness 23), the
\end{abstract}

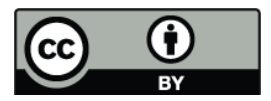

Correspondence to: $\mathrm{P}$. J. McBride (patrick.mcbride@colorado.edu) spectral method provided valid retrievals for $84 \%$ of the data ( $24 \%$ for the standard method). For the SGP data (mean optical thickness 44 ), both methods provided a high return of $90 \%$ for the spectral method and $78 \%$ for the standard method.

\section{Introduction}

Clouds are an important regulator to the flow of radiant energy in the atmosphere through the processes of scattering and absorption of shortwave and longwave radiation. They cool the Earth by reflecting incoming solar radiation to space and warm the surface of the Earth and lower atmosphere by their emission of infrared radiation. Despite decades of cloud observations, the understanding of their role in the climate system remains incomplete. One problem is that clouds have not been studied from the surface in any global, systematic way. In contrast, aerosol properties are observed on a near-global scale through the Aerosol Robotic Network (AERONET, Holben, 1998), which has proven indispensable for validating aerosol retrievals from space. Cloud data sets such as the International Satellite Cloud Climatology Project (ISCCP, Schiffer and Rossow, 1983) rely entirely on spaceborne observations. Ground-based cloud observations provide the surface radiative cloud forcing more directly and therefore more accurately than satellite retrievals. In addition, they can be used to validate satellite retrievals systematically. Due to their high temporal and spatial resolution, surface-data also enables studies of the effects of aerosols on clouds, which the Intergovernmental Panel on Climate Change (IPCC) lists as the largest uncertainty in forecasting climate change (Forster et al., 2007).

Published by Copernicus Publications on behalf of the European Geosciences Union. 
Two parameters are needed to calculate the radiative impacts of clouds, the optical thickness, or equivalently, column integrated extinction $(\tau)$ and effective radius $\left(r_{\text {eff }}\right)$ (Hansen and Hovenier, 1974):

$$
r_{\mathrm{eff}}=\frac{\int_{0}^{\infty} Q_{\mathrm{ext}}(r) r^{3} n(r) d r}{\int_{0}^{\infty} Q_{\mathrm{ext}}(r) r^{2} n(r) d r}
$$

where $Q_{\text {ext }}$ is the extinction efficiency and $n(r)$ is the cloud particle size distribution. Optical thickness and effective radius can be derived from cloud reflectance because reflectance monotonically increases with optical thickness up to an asymptotic limit that is determined by the spectrally dependent bulk water absorption $\left(k_{\mathrm{b}}\right)$ and cloud droplet size. In the weak absorption and geometric optics limits of the solar wavelength range, the absorption coefficient is proportional to the effective radius (Twomey and Bohren, 1980). This dependence results in cloud reflectance being primarily dependent on effective radius in the spectral regions where liquid water is absorbing and primarily dependent on optical thickness in spectral regions where water is nonabsorbing. This is the basis of most cloud reflectance based retrieval algorithms (for example, Hansen and Pollack, 1970; Twomey and Cocks, 1989; Nakajima and King, 1990, among many others). Since the radiation reflected by clouds has mostly interacted with the uppermost cloud layers, reflectance-based retrievals of droplet size are preferentially weighted by cloud top. Platnick (2000) modeled photon transport through clouds and derived the contribution of each cloud layer to the observed transmittance or reflectance. They show that cloud transmittance is more evenly weighted throughout the cloud. Because of this weighting, transmittance provides a perspective that is distinct from cloud reflectance.

This study introduces a new method for deriving cloud properties from zenith-viewing spectral transmitted radiance. Cloud transmittance is more difficult than reflectance to exploit for cloud retrievals, for two reasons. Firstly, there is no one-to-one mapping between transmittance and optical thickness. For optically thin clouds, increasing the concentration of scattering particles and thus the optical thickness results in more diffuse radiation that is scattered into the zenith-viewing detector. Beyond an optical thickness of about four, attenuation dominates, and the transmitted signal decreases with increasing optical thickness. An observed radiance can originate from two different values of optical thickness, and a transmittance-based retrieval is ambiguous. Secondly, in the limit of large optical thickness, the transmitted signal is completely attenuated, regardless of wavelength and droplet size. Reflectance, on the other hand, approaches a value which is non-zero and depends on the effective radius. Therefore, information related to cloud particle size is not as easily extracted from transmittance measurements.
Several algorithms have been developed to obtain cloud optical thickness from transmitted solar radiation. Leontyeva and Stamnes (1994) used transmitted broadband irradiance which, unlike transmitted radiance, has a one-to-one relationship with optical thickness. Barker and Marshak (2001) used a combination of irradiance and radiance at two wavelengths to retrieve cloud optical thickness under broken cloud conditions and over a vegetated surface. Marshak et al. (2004) demonstrated a technique to retrieve optical thickness and effective cloud fraction from transmitted radiance at $673 \mathrm{~nm}$ and $870 \mathrm{~nm}$ over vegetated surface, where a ratio of the difference to the sum of the two radiances was used. They show that this technique overcomes the ambiguity in retrieved optical thickness. This same approach was applied to AERONET data by Chiu et al. (2010) who used radiance at $440 \mathrm{~nm}$ instead of $673 \mathrm{~nm}$. Efforts have been made to retrieve both optical thickness and cloud particle effective radius. Rawlins and Foot (1990) used the ratio of cloud transmittance at $1550 \mathrm{~nm}$ to $1040 \mathrm{~nm}$ and the transmittance at $1040 \mathrm{~nm}$ to retrieve optical thickness and effective radius. They found, however, that the effective radius retrievals were not significant given their high uncertainty. Kikuchi et al. (2006) used two pairs of absolute transmittance, $1020 \mathrm{~nm}$ with $1600 \mathrm{~nm}$ and $1020 \mathrm{~nm}$ with $2200 \mathrm{~nm}$, and retrieved both optical thickness and effective radius. Although they did not publish the effective radius uncertainties, their results pertain to an optical thickness from 10 to 40 . As we will discuss below, the range from 25 to 40 is associated with the lowest retrieval uncertainty, and a dual-channel method is expected to work if the measurement uncertainty is sufficiently small. For smaller or higher optical thickness values, however, a dual-channel method generally leads to large uncertainties.

The results presented in this paper demonstrate the utility of spectral radiance to retrieve cloud optical thickness and cloud particle effective radius from clouds using observations from a single instrument, the Solar Spectral Flux Radiometer (SSFR). The technique introduced in this paper capitalizes on the contiguous and overlapping spectral measurements of the SSFR. It is similar to methods previously employed to determine cloud thermodynamic phase (Pilewskie and Twomey, 1987; Ehrlich et al., 2008) in that, in addition to the relative magnitude of spectral signal, the spectral shape of reflected radiance is exploited. In this study we derive cloud optical thickness and droplet effective radius using the spectral slope of the transmitted radiance between $1565 \mathrm{~nm}$ and $1634 \mathrm{~nm}$, normalized to its value at $1565 \mathrm{~nm}$. This technique removes the non-uniqueness of the retrieval with respect to optical thickness and increases the sensitivity to effective radius (even outside the optical thickness range from 10 to 40) and therefore, reduces uncertainty compared to other retrieval methods. In Sect. 2, we describe the instruments, field experiments, associated data, and the radiative transfer model employed in this study. The retrieval techniques and the derivation of retrieval uncertainty are presented in Sect. 3, results in Sect. 4, and conclusions in Sect. 5. 


\section{Instrumentation, experiments, and model}

The new retrieval method used solar spectral radiance data collected with the Solar Spectral Flux Radiometer (SSFR, Sect. 2.3) (Pilewskie et al., 2003) onboard the Woods Hole Oceanographic Institution research vessel Knorr, and data from the ARM Shortwave Spectrometer (SWS, Sect. 2.4) at the DOE ARM Southern Great Plains (SGP) (Stokes and Schwartz, 1994) site (Sect. 2.2). The SSFR was originally designed for airborne zenith and nadir solar spectral hemispherical irradiance measurements. For ground-based and ship-borne observations, one of the irradiance light collectors was replaced with a zenith-viewing radiance fore-optic. The surface-based version of SSFR measured downward radiance and irradiance simultaneously. This is the configuration that was used onboard the Knorr during the International Chemistry Experiment in the Arctic Lower Troposphere (ICEALOT, Sect. 2.1). SWS, in contrast, measured downward radiance only. To validate SSFR and SWS retrievals, simultaneous microwave radiometer (MWR, Sect. 2.5) observations and satellite retrievals from the Moderate Resolution Imaging Spectroradiometer (MODIS, Sect. 2.6) were used.

\subsection{International Chemistry Experiment in the Arctic Lower Troposphere (ICEALOT)}

ICEALOT was conducted by the National Oceanic and Atmospheric Administration within the International Polar Year 2008. The cruise began at the Woods Hole Oceanographic Institution in Woods Hole, MA, and headed south into Long Island Sound. From there it went north, into the ice-free regions of the Northern Atlantic and Arctic Oceans during March and April, 2008. The focus of ICEALOT was on the transport of springtime pollutants into the Arctic, including the impact of aerosol particles on cloud microphysical properties. The ship payload consisted mainly of gasphase chemistry and in-situ aerosol instrumentation, but also included cloud remote sensing instruments, a microwave radiometer, a millimeter cloud radar, and a Vaisala ceilometer. The radiance data of the SSFR was used for cloud remote sensing while the irradiance data constrained the radiative energy balance under cloud and aerosol-laden conditions.

\subsection{Southern Great Plains site of the ARM climate research facility}

One of the missions of the ARM program is the development and maintenance of highly instrumented field stations to constrain the radiative forcing of clouds and aerosols by measurements at the surface. One such facility is the SGP site, located in Lamont, OK. The SWS (Sect. 2.4) was added to the instrument suite in 2006 to enhance cloud remote sensing capabilities. Diffuse and direct irradiance at selected wavelengths are routinely measured by the Multi-filter Rotating
Shadowband Radiometer (MFRSR) (Harrison et al., 1994). The other SGP instruments relevant to this study include a CIMEL AERONET sun photometer, a Vaisala ceilometer, a YES, Inc Total Sky Imager and a microwave radiometer.

\subsection{Solar Spectral Flux Radiometer (SSFR)}

The SSFR is a spectrometer system with moderate spectral resolution (8-12 nm) and sampling frequency $(1 \mathrm{~Hz})$. It covers a wavelength range from $350 \mathrm{~nm}$ to $1700 \mathrm{~nm}$. The radiation is collected by a collimator for the radiance measurements and by a light collector with hemispherical field of view and cosine weighting characteristics for irradiance. The light collectors are connected to the spectrometer systems by optical fibers. During ICEALOT, the light collectors were mounted on a zenith-viewing leveling platform on one of the towers of the ship, with the spectrometer unit located in a temperature-controlled environment. Each system consists of two monolithic miniature Zeiss spectrometers to cover the full wavelength range: a flat-field grating with a linear silicon diode array detector for the spectral range from $350 \mathrm{~nm}$ to $1000 \mathrm{~nm}$, and an Indium-Gallium-Arsenide (InGaAs) linear diode array for the range from $900 \mathrm{~nm}$ to $1700 \mathrm{~nm}$ (ship version,"PGS1.7"). The silicon module is temperature-stabilized at $27.0^{\circ} \mathrm{C} \pm 0.3^{\circ} \mathrm{C}$ to keep dark currents stable. Its spectral resolution as prescribed by the fullwidth-half-maximum (FWHM) is $8 \mathrm{~nm}$, with $3 \mathrm{~nm}$ sampling resolution. Each observation point has a quasi-Gaussian spectral bandpass or slit function. The InGaAs diode array is thermoelectrically cooled to $+10.0^{\circ} \mathrm{C} \pm 0.1{ }^{\circ} \mathrm{C}$ (PGS1.7). The temperature of the pre-amplifier and control electronics is stabilized to reduce dark current drift. The FWHM was $12 \mathrm{~nm}$, with $5.5 \mathrm{~nm}$ sampling (PGS1.7).

The irradiance light collectors are designed to provide a cosine-weighting of the incoming hemispherical radiance. This was realized by a circular aperture in a miniature integrating sphere, covered by a quartz dome for environmental protection. Deviations from ideal cosine response were measured in the laboratory and were corrected in postprocessing. While the irradiance light collector has a $2 \pi$ steradian field of view (FOV), the collimator limits the FOV to $3^{\circ}$ for radiance measurements. The angular response of the collimator was also measured in the laboratory before and after each deployment. The rejection of radiation coming from outside the FOV was determined to be better than $10^{-3}$.

Dark current measurements were made every $5-30 \mathrm{~min}$ by activating a light shutter in front of the spectrometers for $10-60 \mathrm{~s}$. The rate of the dark current measurements must be higher than the characteristic frequency of the temperature variation within the instrument. For example, if the temperature stabilization cycles with $T=30 \mathrm{~min}$, the dark current acquisition frequency needs to be set to at least 4 per $30 \mathrm{~min}$. This is important in the long-wavelength end of the spectral range because they are the most affected by temperature-induced changes in the dark currents, due to 
the strong wavelength dependence in thermal emission. The dark spectra were subtracted from the measured spectra. Between individual dark current measurements, the dark spectra were linearly interpolated.

The radiance calibration was performed at the NASA Ames Research Center with a NIST-traceable 30 inch diameter integrating sphere, the same sphere used to calibrate the MODIS airborne simulator (King et al., 1996). The sphere contains 12 NIST traceable quartz-halogen lamps, three of which were illuminated for the SSFR radiance calibration. The radiance output from the sphere is known to within 1$2 \%$. These calibrations were performed before and after deployment. For normal SSFR airborne operations, field calibrations were conducted regularly to track the stability of the instrument. However, no field-portable sphere was available the ship-board deployment.

Irradiance calibrations were performed before and after each experiment in the laboratory with a NIST-traceable blackbody (tungsten-halogen $1000 \mathrm{~W}$ FEL lamp). The nominal accuracy is $2-3 \%$, due primarily to the uncertainty of the calibration light source. Typically, a calibration stability of $1 \%$ or $2 \%$ is achieved over the course of a multi-week field mission. Noise-induced errors are only relevant near the limits of sensitivity of the individual spectrometers, below $370 \mathrm{~nm}$ and above $950 \mathrm{~nm}$ for the Silicon spectrometers and below 950 and above $1650 \mathrm{~nm}$ for the InGaAs spectrometers. The precision of the SSFR is $0.1 \%$.

\subsection{Shortwave Spectroradiometer (SWS)}

The SWS derives its heritage from the SSFR and was equipped with the InGaAs PGS2.2 spectrometer, extending its spectral range to $2200 \mathrm{~nm}$. The SWS had only one zenith pointing light collector with a field of view of $1.4^{\circ}$, about half that of the radiance light collector on the SSFR. The light rejection of the collimator, which limits the field-of-view, was determined to be less than $10^{-3}$. For measurements under cloud-free or broken cloud conditions, there may be stray light contamination in the near-infrared where molecular scattering is weak, but for the present study under uniform cloud cover (see the discussion on filtering in Sect. 3.4) this level of rejection was adequate. A new SSFR radiance fore-optic with an improved rejection of $10^{-5}$ was deployed before another NOAA ship cruise (described in a forthcoming paper), in May, 2010. However, to this day, SWS still operates with the old fore-optics with a stray light rejection $10^{-3}$. SWS is calibrated once a year with the NASA Ames 30 inch sphere mentioned above. In addition, SWS is regularly calibrated against a portable 12 inch sphere (Labsphere, Inc.). Measuring the response to the two spheres at the same time and under the same conditions allows the calibration to be transferred from the NIST traceable sphere to the $12 \mathrm{inch}$ sphere. The weekly calibration is conducted by the staff at the SGP, to track changes in the performance of the instrument. The uncertainty of the radiance measurements of the
SWS spectrometers is the same as that of the SSFR, $1 \%-3 \%$. The InGaAs diode array (PGS2.2) of the SWS is thermoelectrically cooled to $-10.0^{\circ} \mathrm{C} \pm 0.1^{\circ} \mathrm{C}$ and the silicon module is temperature-stabilized at $27.0^{\circ} \mathrm{C} \pm 0.3{ }^{\circ} \mathrm{C}$. It is kept in a climate controlled trailer at the SGP. The InGaAs spectrometers have a small drift associated with thermal emission in their response at the longest wavelengths $(\sim 2 \mu \mathrm{m})$. To correct for this drift, dark current readings are taken every $5 \mathrm{~min}$ for $15 \mathrm{~s}$. The dark currents were acquired when a shutter, controlled by the system software of the SWS, closed for a defined duration, called a dark cycle. The dark current acquisition frequency and duration are stored in a control file and can be easily changed by a remote user. A linear interpolation scheme is used between individual dark cycles to account for the temperature changes.

\subsection{Microwave radiometer}

The ARM microwave radiometer measures microwave emissions from the atmosphere at two frequencies to retrieve column integrated liquid water and water vapor. The observations are made at $23.8 \mathrm{GHz}$ and $31.4 \mathrm{GHz}$, the former being more sensitive to water vapor and the latter more sensitive to liquid water. The instrument measures the emission for $1 \mathrm{~s}$, every $16 \mathrm{~s}$, with a field of view of $5.9^{\circ}$ for the $23.8 \mathrm{GHz}$ channel and $4.5^{\circ}$ for the $31.4 \mathrm{GHz}$ channel. The uncertainty of the liquid water path observations is approximately $\pm 20 \mathrm{~g} \mathrm{~m}^{-2}$ (Turner et al., 2007). The ARM retrieval algorithm was described in Westwater (1993) and Liljegren and Lesht (1996). The NOAA microwave radiometer used during ICEALOT was very similar to the ARM instrument at the SGP. It measures at the same frequencies but the fieldsof-view were slightly different, $5.7^{\circ}$ and $4.4^{\circ}$ for the 23.8 and $31.4 \mathrm{GHz}$ channels respectively. The underlying premise of the NOAA two-frequency retrieval was the same; details can be found in Westwater et al. (2001).

\subsection{Moderate Resolution Imaging Spectroradiometer (MODIS)}

MODIS on Aqua and Terra measures radiation in the visible, near infrared, and thermal infrared to derive cloud properties at $1 \mathrm{~km}$ resolution. The $1 \mathrm{~km}$ cloud properties can be found in the MOD06 and MYD06 MODIS products. The cloud retrieval algorithm was presented in Nakajima and King (1990) and Platnick et al. (2003). The algorithm uses cloud reflectance at two wavelengths, one in a non-absorbing region for water, and the other in an absorbing region. For retrievals over land, the wavelengths are $650 \mathrm{~nm}$ and $2100 \mathrm{~nm}$ (Platnick et al., 2003). 


\subsection{Radiative transfer calculations}

The standard method for retrieving cloud parameters (see for example, Nakajima and King, 1990; Twomey and Cocks, 1989) requires calculating radiances or irradiances over ranges of cloud optical thickness, effective radii, solar zenith angles, viewing angles, and for at least two wavelengths. Cloud properties are inferred by finding the best match between pre-calculated and observed values. To avoid the effects of molecular absorption, the retrieval wavelengths are chosen outside of the regions of strong molecular absorption.

The plane-parallel radiative transfer model used in this study was adapted from the work of Coddington et al. (2008) and Bergstrom et al. (2003). Downward radiance at the surface was calculated for optical thickness ranging from 0.1 to 0.9 at an interval of 0.1 and from 1 to 100 at an interval of 1 . The effective radius was varied from $1 \mu \mathrm{m}$ to $30 \mu \mathrm{m}$ at an interval of $1 \mu \mathrm{m}$. The radiance data were interpolated to a resolution of 0.1 in optical thickness and $0.1 \mu \mathrm{m}$ in effective radius. The cosine of the solar zenith angle $\left(\mu_{0}\right)$ was varied from 0.05 to 1.0 in steps of 0.05 . The calculations were performed across the full wavelength range of SSFR and SWS. Inputs to the model included the spectral surface albedo, cloud optical thickness, cloud droplet effective radius, cloud base and top height, temperature, pressure, and gas molecular number concentrations. The SGP and ICEALOT retrievals were performed using a standard midlatitude summer atmosphere for the gaseous concentrations and radiosonde data from each site for the temperature and pressure profiles.

The optical properties of the cloud droplets were calculated with a Mie code (Evans, 1998) and, hence, the results presented here are valid only for spherical water droplets. The calculations produced (1) single scattering albedo $\left(\varpi_{0}\right)$, the probability that a photon will be scattered in a single interaction with a particle, (2) the first 16 moments of the scattering phase function, the first of which is the asymmetry parameter $(g)$, and (3) extinction. The Mie calculations were performed assuming a gamma drop size distribution (Chýlek and Ramaswamy, 1982) with an effective variance of 0.1 .

The transmitted radiance is dependent on the albedo of the surface surrounding the instrument. The surface at the SGP site consists of a few varieties of vegetation that vary with the growing season. The data was acquired during the spring and summer when the surface was predominately green vegetation. Concurrent surface albedo measurements that match the spectral range and resolution of the SWS were not available for the SGP cases. MODIS (Sect. 2.6) provides $500 \mathrm{~m}$ spatial resolution surface albedo across the range of the SWS, but at only a few discrete channels (MODIS products MCD/MOD43A4). For the spectral region between $1565 \mathrm{~nm}$ and $1634 \mathrm{~nm}$, a green grass albedo from the US Geological Survey (USGS) (Clark et al., 2007) was used. The interpolated MODIS/USGS-derived surface albedo is shown in Fig. 1 (red spectrum). The ICEALOT data was collected over

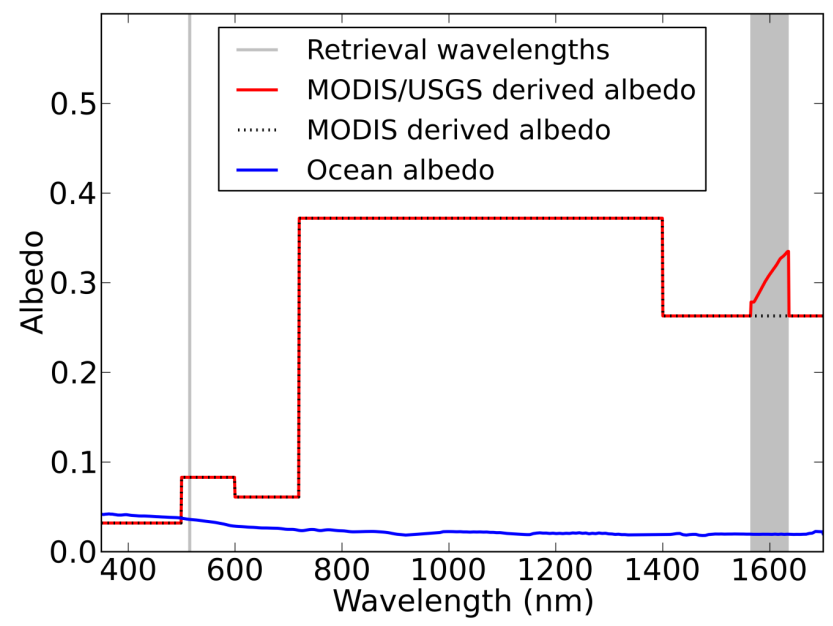

Fig. 1. Surface albedo plots used in the radiative transfer model, the ICARTT ocean albedo used for ICEALOT retrievals (blue), the MODIS/USGS derived vegetated surface albedo (red), the MODIS derived vegetated surface albedo (black dashed line). Gray lines mark the wavelengths used in the slope-transmittance retrieval algorithm.

ocean, which has an albedo near $0.03-0.04$ over the spectral range of the SSFR/SWS. The spectral ocean albedo (Fig. 1, blue spectrum) was retrieved during the International Consortium for Atmospheric Research on Transport and Transformation (ICARTT) experiment (Coddington et al., 2008).

\section{Retrieval techniques}

In this section, the application of the dual-wavelength retrieval (hereafter referred to as "standard retrieval") to reflectance and transmittance observations will be discussed (Sect. 3.1). Throughout this paper, transmittance $T$ and reflectance $R$ are defined as

$T=\pi I_{\text {trans }} / \mu_{0} F_{0}$

$R=\pi I_{\text {refl }} / \mu_{0} F_{0}$

where $I_{\text {trans }}$ and $I_{\text {refl }}$ are the transmitted zenith radiance and reflected nadir radiance, $\mu_{0}$ is the cosine of the solar zenith angle, and $\mu_{0} F_{0}$ is the normal incident irradiance at the top of the atmosphere.

To better understand the differences between cloud reflectance (for which the dual-channel method was originally intended) and transmittance, some typical clouds will be examined in Sect. 3.2, and the retrieval uncertainties will be used to illustrate the shortcomings of the standard method when applied to cloud transmittance. The spectral properties of liquid water droplets in the near-infrared wavelength range (Sect. 3.3) motivate the use of a spectral slope, rather than a single channel, in the near-infrared. The new retrieval ("spectral retrieval" hereafter, Sect. 3.4) differs from the standard retrieval in that the transmittance in the near-infrared is 
(a) Radiance at $515 \mathrm{~nm}$

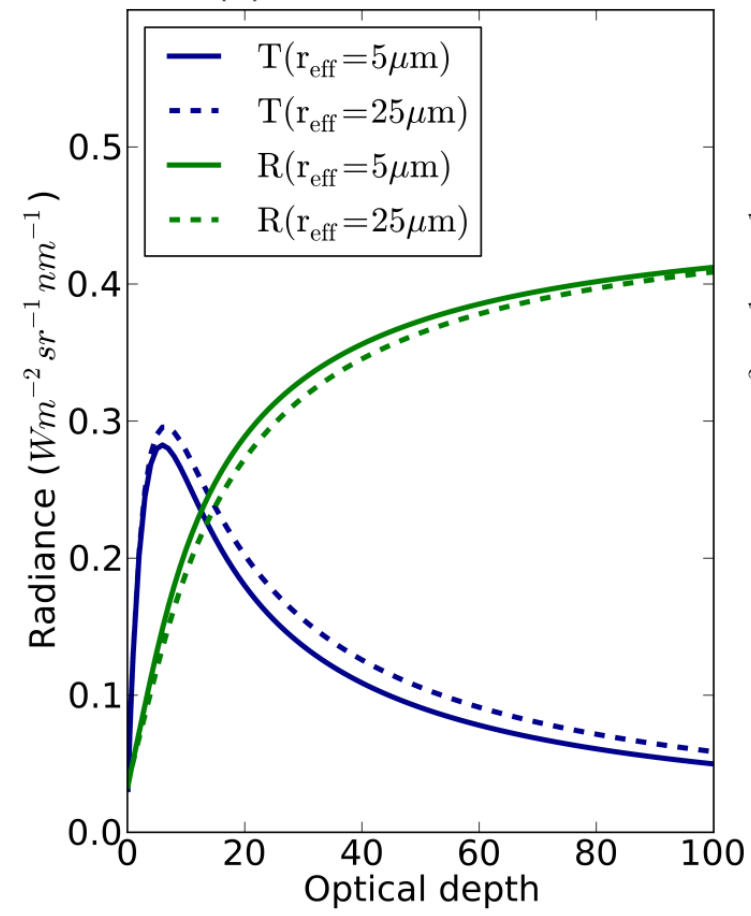

(b) Radiance at $1628 \mathrm{~nm}$

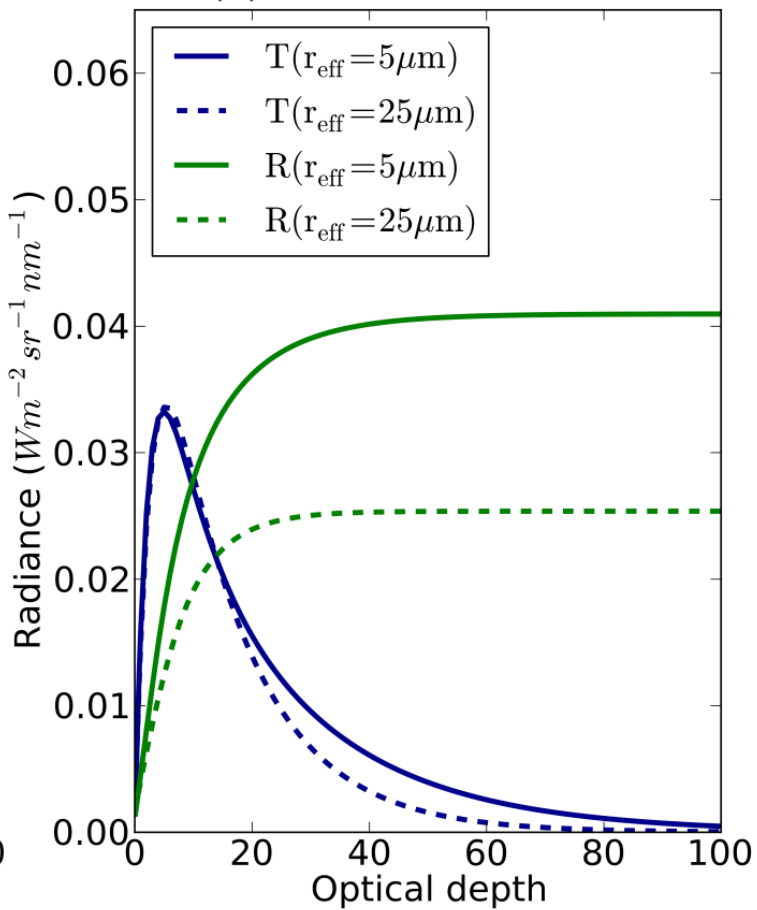

Fig. 2. Modeled transmitted (blue) and reflected (green) radiance at (a) $515 \mathrm{~nm}$ and (b) $1628 \mathrm{~nm}$ for effective radii values of $5 \mu \mathrm{m}$ (solid lines) and $25 \mu \mathrm{m}$ (dashed lines). These were computed for a $\mu_{0}$ of 0.75 and an ocean surface albedo.

replaced by the spectral slope of transmittance, normalized to the transmittance itself. At this point, the spectral retrieval has only been applied to transmittance, not to reflectance.

\subsection{Transmitted and reflected radiance as functions of effective radius and optical thickness}

Figure 2 shows the modeled cloud reflectance and transmittance for two effective radii $(5 \mu \mathrm{m}$ and $25 \mu \mathrm{m})$ and two wavelengths $(515 \mathrm{~nm}$ and $1628 \mathrm{~nm})$ as functions of optical thickness. These calculations illustrate how the dependencies on optical thickness and effective radius differ between transmitted and reflected radiance in these two spectral regions. Figure 2 shows the one-to-one relationship between cloud optical thickness and reflected radiance at $515 \mathrm{~nm}$. The calculations show that a cloud with droplet effective radius of $5 \mu \mathrm{m}$ (solid line) has nearly the same reflectance as a cloud with droplet effective radius $25 \mu \mathrm{m}$ (dashed line), over the optical thickness range 0.1 to 100 . At $1628 \mathrm{~nm}$, size-dependent droplet absorption allows a distinction of the effective radius in reflectance (solid and dashed line are well separated). For transmittance, the distinction is not as clear since the solid and dashed lines are less well separated; in addition, the transmitted radiance approaches zero for large optical thickness, irrespective of size (albeit at different size-dependent rates).
Figure 2 also shows the aforementioned non-monotonic behavior of the transmitted radiance with respect to optical thickness, which leads to an ambiguous retrieval. For example, a radiance of $0.15 \mathrm{~W} \mathrm{~m}^{-2} \mathrm{~nm}^{-1} \mathrm{sr}^{-1}$ at $515 \mathrm{~nm}$, corresponds to an optical thickness of either 2 or 25 . A more subtle reason for the reduced sensitivity of transmitted radiance to effective radius is the near-cancellation of opposing effects: A larger effective radius increases the forward scattering and thus the transmittance; at the same time, a larger droplet also absorbs more (Rawlins and Foot, 1990), which leads to a decrease in transmittance. On the other hand, enhanced forward scattering and absorption both lead to a decreased reflected radiance.

Figure 3 represents the standard retrieval in the form of lookup tables for the reflectance (3a) and transmittance (3b). They show the reflectance and transmittance at $1628 \mathrm{~nm}$ plotted versus that at $515 \mathrm{~nm}$, for a range of effective radii and optical thickness. The reflectance at $515 \mathrm{~nm}$ and $1628 \mathrm{~nm}$ monotonically increase with optical thickness. The radiance at $515 \mathrm{~nm}$ approaches an asymptotic value of about 1 for large optical thickness while the radiance at $1628 \mathrm{~nm}$ approaches values less than 1 that are determined by the effective radius. This enables the simple discrimination of droplet size from cloud reflectance. The transmittance (Fig. 3b) is more complicated. Lines of constant effective radius are nearly indistinguishable for clouds with optical thickness below 10 and droplet radii larger than $3 \mu \mathrm{m}$. They separate 


$$
\begin{aligned}
& -\mathrm{r}_{e f f}=3 \mu \mathrm{m}-\mathrm{r}_{e f f}=10 \mu \mathrm{m}-\mathrm{r}_{e f f}=20 \mu \mathrm{m}-\mathrm{r}_{\text {eff }}=30 \mu \mathrm{m} \\
& -\mathrm{r}_{e f f}=5 \mu \mathrm{m}-\mathrm{r}_{e f f}=15 \mu \mathrm{m}-\mathrm{r}_{\text {eff }}=25 \mu \mathrm{m}
\end{aligned}
$$

\section{(a) Cloud reflectance lookup table}

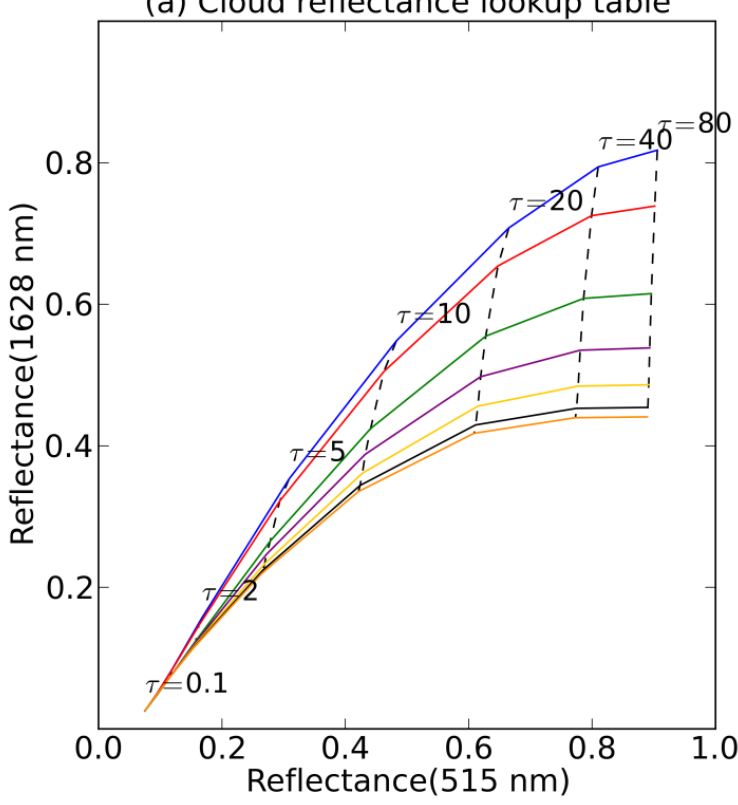

(b) Cloud transmittance lookup table

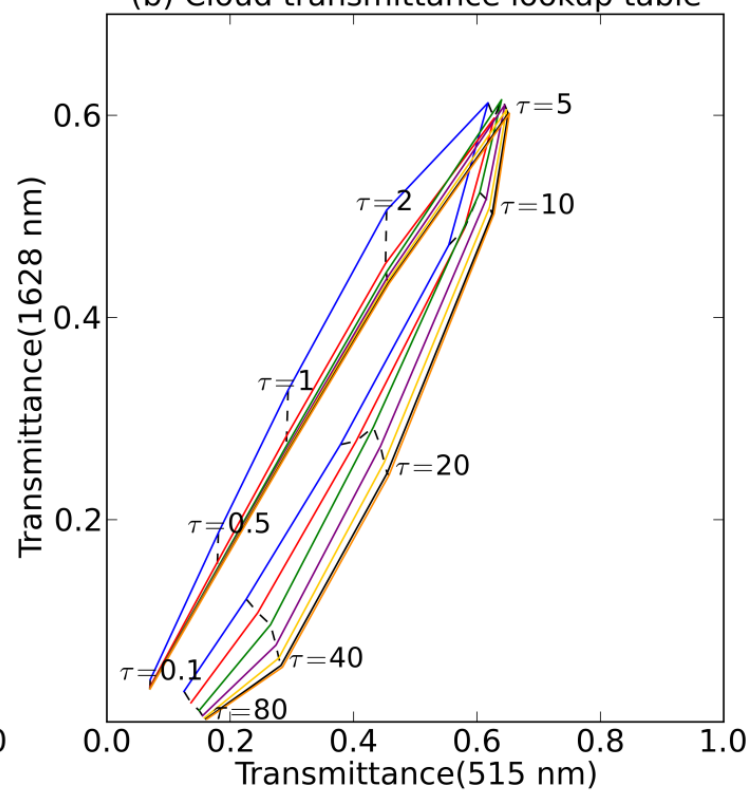

Fig. 3. Lookup table for the standard retrieval method using (a) cloud reflectance and (b) cloud transmittance. Constant effective radius lines are solid and constant optical thickness lines are dashed. These were computed for a $\mu_{0}$ of 0.75 and an ocean surface albedo.

more clearly for optical thickness values between 20 and 40 . The lines of constant optical thickness are much more clearly delineated than the effective radius lines. The density of lines in this plot implies that there is sensitivity to the optical thickness, less sensitivity to effective radius for optical thickness below 10, and moderate sensitivity to effective radius for optical thickness between 20 and 40. In the following section, this sensitivity will be analyzed quantitatively.

\subsection{Quantifying sensitivity to optical thickness and effective radius in the standard method}

To quantify the sensitivity of reflectance and transmittance with respect to cloud optical thickness and effective radius, cloud reflectance and transmittance for a cloud with optical thickness values of 10,20, and 40 and with a droplet effective radius of $10 \mu \mathrm{m}$ were simulated with the radiative transfer model. Optical thickness and effective radius, as well as the associated uncertainties, were retrieved with the standard method applied to reflectance and transmittance.

The standard retrieval was performed with a least squares fit between observed (obs) and modeled (mod) reflectance and transmittance:

$\chi=\sqrt{\frac{1}{2}\left(\left(\frac{T_{\mathrm{obs}, 515}-T_{\bmod , 515}}{T_{\bmod , 515}}\right)^{2}+\left(\frac{T_{\mathrm{obs}, 1628}-T_{\bmod , 1628}}{T_{\bmod , 1628}}\right)^{2}\right)}$
The uncertainty in this equation can be propagated to $x$ through:

$\delta \chi=\sum_{n=0}^{1}\left(\frac{\partial \chi}{\partial T_{n}} \delta T_{n}\right)^{2}$

from Taylor (1996), where $\delta \chi$ is the uncertainty in $\chi$ and $\delta T$ is the $3 \%$ radiometric uncertainty, assuming that the uncertainties can be represented as Gaussians and are uncorrelated.

The optical thickness range $\left(\tau_{\chi+\delta \chi}, \tau_{\chi-\delta \chi}\right)$ and effective radius range $\left(r_{\chi}+\delta \chi, r_{\chi}-\delta \chi\right)$ associated with the measurement uncertainty was obtained by minimizing $\chi-\delta \chi$ and $\chi+\delta \chi$ in Eq. (3) instead of $\chi$. The uncertainty was defined as half the difference of the range:

$$
\begin{aligned}
& \delta r_{\mathrm{eff}}=\frac{\left|r_{(\chi+\delta \chi)}-r_{(\chi-\delta \chi)}\right|}{2} \text { and } \\
& \delta \tau=\frac{\left|\tau_{(\chi+\delta \chi)}-\tau_{(\chi-\delta \chi)}\right|}{2}
\end{aligned}
$$

Since $\chi$ must be 0 or greater by definition, cases with negative values of $\chi-\delta \chi$ were considered indistinguishable solutions and all these optical thickness and effective radius pairs were included in the retrieved range. For these cases, $r_{\chi}+\delta \chi$ and $r_{\chi}-\delta \chi$ were replaced with the maximum and minimum effective radius in this range. The same was done for optical thickness. 
The resulting uncertainties are presented in Table 1. For the standard retrieval applied to reflectance, the relative uncertainty of the effective radius was $22 \%$ and improved to $15.0 \%$ and $11.0 \%$ for optical thickness of 20 and 40 . For the standard retrieval applied to transmittance, the relative uncertainty of the effective radius was as high as $71.2 \%$ for an optical thickness 10 and improved to $30.5 \%$ and $12.7 \%$ at an optical thickness of 20 and 40, respectively. This confirms what was shown qualitatively in Fig. 3b. In transmittance, the greatest separation between lines of effective radius occurs at values of optical thickness between 30 and 40, where the uncertainty in effective radius is at its minimum. The effective radius uncertainty reaches its maximum at an optical thickness of 10 where the effective radius lines in Fig. $3 \mathrm{~b}$ are poorly delineated.

Reflectance and transmittance are both sensitive to optical thickness. The sensitivity of the standard retrieval decreases with optical thickness as reflectance approaches its asymptotic limit, illustrated by the increase in the relative uncertainty of optical thickness from $5.7 \%$ to $12.2 \%$ for an optical thickness of 10 and 40, respectively. For the standard retrieval applied to transmittance the lines of constant optical thickness in Fig. 3b are closest together at an optical thickness of 5, separate more up to an optical thickness 40 and then become less distinguishable as the transmittance approaches its asymptotic value of zero. This is reflected in the modeled optical thickness uncertainty which is highest at an optical thickness of 10 and decreases for optical thickness of 20 and 40 .

\subsection{Spectral transmittance dependencies on optical thickness and effective radius}

In the previous section, we established that when applying the standard method to transmittance, the uncertainty in effective radius reaches $71 \%$ - far more than for reflectance $(12 \%)$. By introducing an upper uncertainty threshold for the retrieved effective radius, one can define the retrieved value as "acceptable" or "meaningful" if its uncertainty is below that threshold. For example, Table 1 shows that a $50 \%$ tolerable relative uncertainty entails that the effective radius retrievals for an optical thickness of 10 and 20 are both meaningless, since their uncertainties $(71.2 \%$ and $51.8 \%)$ are above the defined threshold.

To overcome this difficulty, the spectral shape of basic optical properties is of crucial importance. Figure 4 shows the coalbedo (1- $\varpi_{0}$, indicative of absorption) and asymmetry parameter $(g)$ across the spectral range of the measurements and at three effective radii. The coalbedo increases with increasing effective radius, as the droplet absorption increases. The asymmetry parameter also increases with increasing effective radius since forward scattering increases with size. The coalbedo varies over several orders of mag-

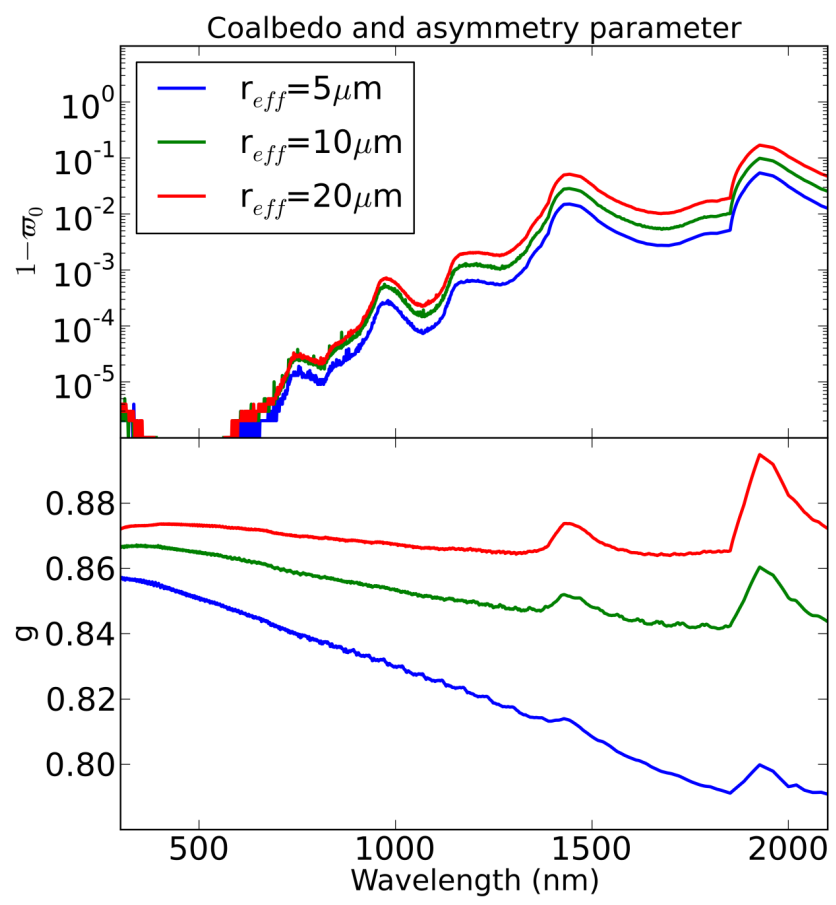

Fig. 4. Coalbedo and asymmetry parameter for liquid water drops from Mie calculations for three different cloud particle effective radii.

nitude across this spectral range with the least absorption in the visible, while the asymmetry parameter varies by approximately $12 \%$.

The spectral shapes of the coalbedo and asymmetry parameter have a direct impact on the transmittance. Figure 5 shows modeled transmittance for four values of optical thickness and two values of effective radius. At wavelengths shorter than about $1100 \mathrm{~nm}$, the different effective radii manifest themselves through scattering. Larger droplet size is associated with stronger forward scattering (larger asymmetry parameters), and thus larger transmittance. However, because droplet absorption increases with wavelength, the opposite effect dominates at wavelengths greater than about $1400 \mathrm{~nm}$, and larger droplet size leads to decreased transmittance. The wavelength at which the impact of absorption exceeds scattering can be identified by the crossover between the two spectra calculated with two different effective radii at a certain optical thickness. This occurs between $1100 \mathrm{~nm}$ and $1400 \mathrm{~nm}$, the exact location is determined by the magnitude of cloud absorption.

Figure 6 shows the modeled transmittance normalized by the transmittance at $1565 \mathrm{~nm}$ for an optical thickness of 35 and effective radii of $5 \mu \mathrm{m}$ and $25 \mu \mathrm{m}$. The cloud droplet absorption is strongest at $1565 \mathrm{~nm}$; thus the transmittance increases with wavelength over the range from $1565 \mathrm{~nm}$ to $1634 \mathrm{~nm}$. The spectral slope carries information about both droplet size and optical thickness; the normalization to the 
Table 1. Relative optical thickness $(\tau)$ and effective radius $\left(r_{\text {eff }}\right)$ uncertainties calculated from simulated retrievals for cloud reflectance and transmittance. The uncertainties were calculated by propagating the $3 \%$ radiometric uncertainty through the retrieval algorithm.

\begin{tabular}{l|l|rr|rr}
\hline & & \multicolumn{2}{|c|}{ Reflectance retrievals } & \multicolumn{2}{c}{ Transmittance retrievals } \\
\cline { 3 - 7 }$\tau$ & $r_{\text {eff }}$ & Relative $\tau$ uncertainty & Relative $r_{\text {eff }}$ uncertainty & Relative $\tau$ uncertainty & Relative $r_{\text {eff }}$ uncertainty \\
& $(\mu \mathrm{m})$ & $(\%)$ & $(\%)$ & $(\%)$ & 71.2 \\
\hline 10 & 10 & 5.7 & 22.0 & 14.9 & 51.8 \\
20 & 10 & 8.0 & 15.0 & 6.8 & 14.3 \\
40 & 10 & 12.2 & 11.0 & 2.3 & \\
\hline
\end{tabular}

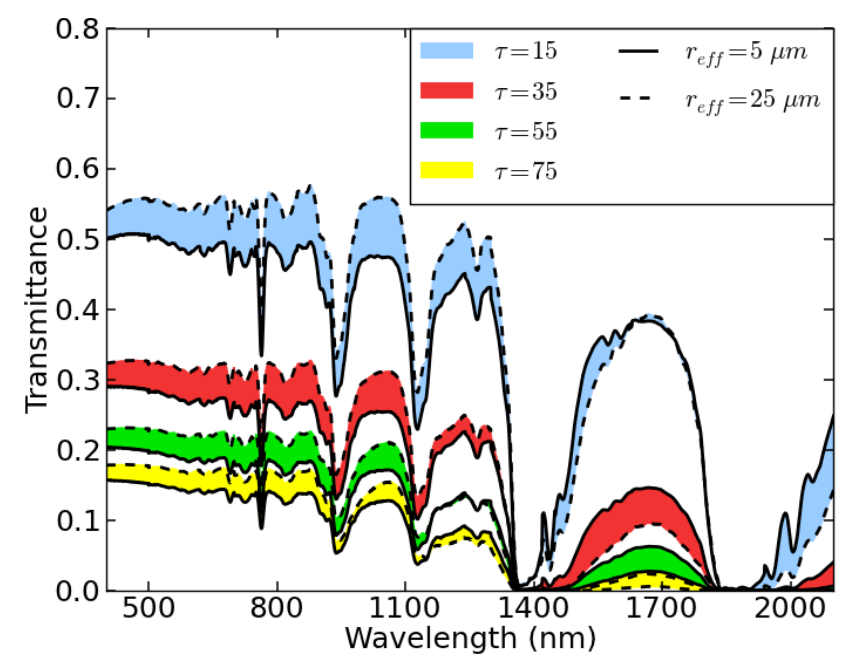

Fig. 5. Modeled transmittance through a liquid water cloud showing the dependencies on cloud optical thickness and cloud particle effective radius. The shaded regions are that of constant cloud optical thickness for a cloud particle effective radii range spanning from 5$25 \mu \mathrm{m}$. These were computed for a $\mu_{0}$ of 0.75 and an ocean surface albedo.

transmittance value at one wavelength has the advantage that the effect of spectrally correlated errors (such as, to some extent, radiometric uncertainty) is removed, whereas the effect of uncorrelated errors (such as dark current fluctuations), contribute to the uncertainty of the derived slope.

\subsection{New spectral retrieval algorithm}

To reduce the error in the linear regression, the spectral range over which transmittance was regressed was selected based on (a) linear behavior of transmittance over a wide range of optical thickness and effective radius and (b) location outside of the bands of strong molecular absorption. Using these criteria, the spectral region between $1565 \mathrm{~nm}$ and $1634 \mathrm{~nm}$ was selected as an optimal region. At the spectral sampling resolution of the SWS, this provided 13 wavelengths as a basis for the calculation of the slope, which was determined from a least-squares linear regression.

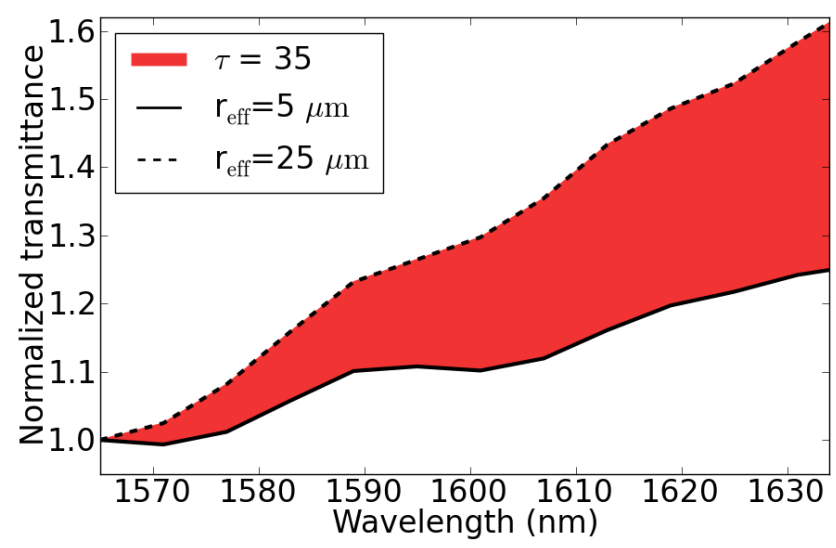

Fig. 6. Normalized transmittance for optical thickness of 35 and for two effective radii, $5 \mu \mathrm{m}$ (solid line) and $25 \mu \mathrm{m}$ (dashed line).

Figure 7 shows the transmittance at $515 \mathrm{~nm}\left(T_{515}\right)$ plotted against the spectral slope $\left(S_{1565}\right)$ around $1565 \mathrm{~nm}$ for the same range of optical thickness and effective radii as in Fig. 3 (note that the slope axis is shown logarithmically). For effective radii less than $25 \mu \mathrm{m}$, the effective radius lines are better separated than in the standard method, implying a larger sensitivity to this parameter.

Similar to the standard method, the spectral retrievals are obtained from a least squares fit of modeled and observed values; in this case transmittance at $515 \mathrm{~nm}$ and the spectral slope at $1565 \mathrm{~nm}$ :

$\chi=\sqrt{\left(\frac{T_{\mathrm{obs}, 515}-T_{\bmod , 515}}{T_{\bmod , 515}}\right)^{2}+\left(\frac{S_{\mathrm{obs}, 1565}-S_{\mathrm{mod}, 1565}}{S_{\bmod , 1565}}\right)^{2}}$

As shown previously, the retrieval uncertainties were estimated using the range of optical thickness and effective radius found by minimizing $\chi \pm \delta \chi$. The radiometric uncertainty was assumed as spectrally correlated for $S_{1565}$, and, therefore, replaced by the spectrally uncorrelated error, ( $0.1 \%$, Pilewskie et al., 2003, dominated by dark current). $\delta \chi$ is determined by 


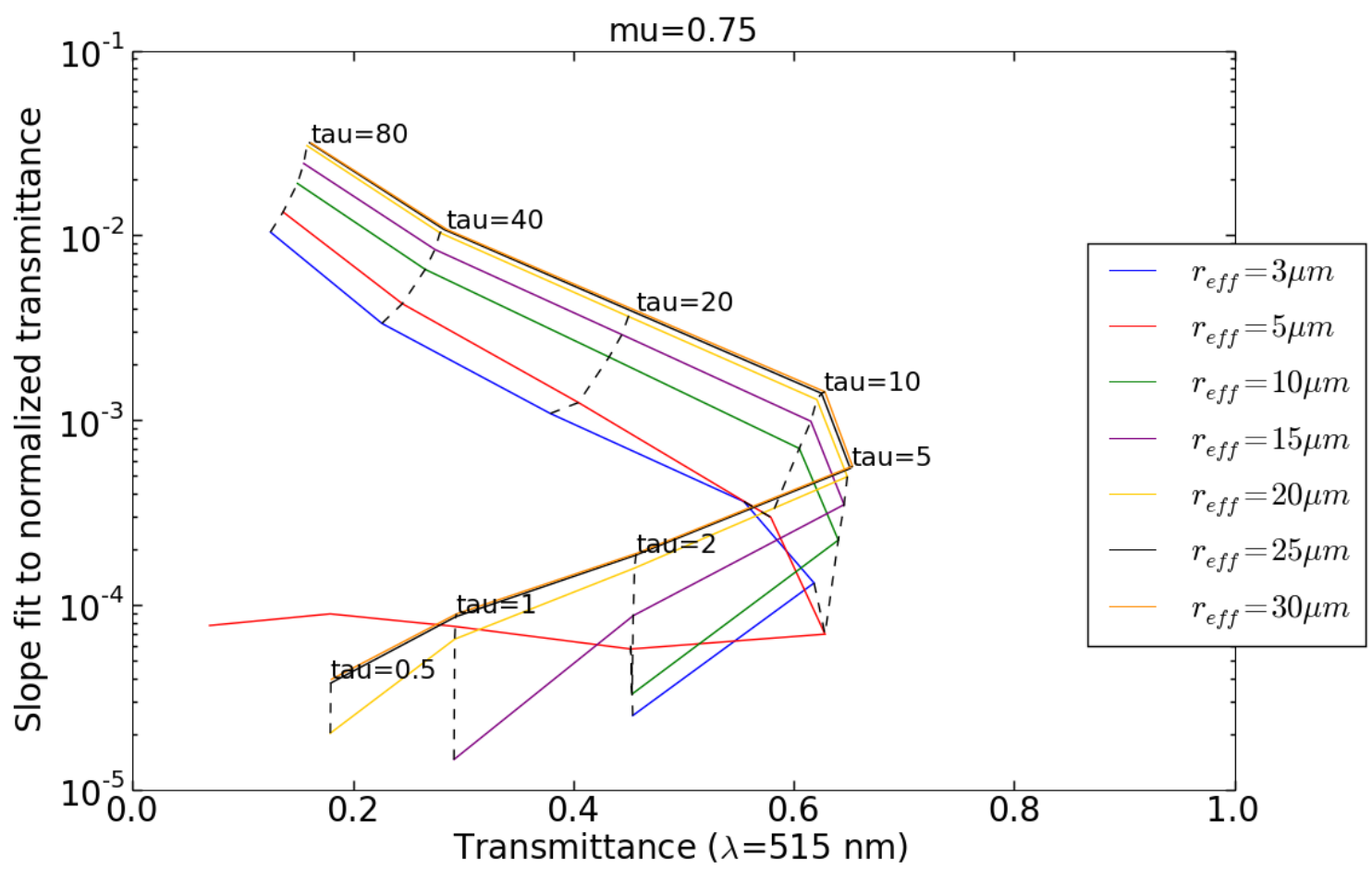

Fig. 7. Lookup table using the transmittance calculated with modeled surface radiance and the slope of the line fit through the normalized transmittance in the range $1565 \mathrm{~nm}$ to $1634 \mathrm{~nm}$. These were computed for a $\mu_{0}$ of 0.75 and an ocean surface albedo.

$\delta \chi=\sqrt{\left(\frac{\partial \chi}{\partial T_{515}} \delta T_{515}\right)^{2}+\sum_{x=1}^{N-1}\left(\frac{\partial \chi}{\partial\left(\frac{T_{x}}{T_{1565}}\right)} \delta\left(\frac{T_{x}}{T_{1565}}\right)\right)^{2}}$

where $\delta \chi$ is the uncertainty in $\chi$ (Eq. 6), $\delta T$ is the transmittance uncertainty resulting from the $3 \%$ radiometric uncertainty, $\delta\left(T_{x} / T_{1565}\right)$ is the $0.1 \%$ uncertainty in the normalized transmittance and $N$ is number of wavelengths.

From the retrieved optical thickness and effective radius, the liquid water path (LWP) is derived. The LWP can be approximated by

$\mathrm{LWP}=\frac{2}{3} \tau r_{\mathrm{eff}}$,

if the effective radius is much larger than the wavelength and if effective radius and liquid water content do not vary within the sampling volume. An alternative formulation of the LWP was derived by Wood and Hartmann (2006) for clouds where effective radius increases linearly with altitude above cloud base (referred to hereafter as a WH06 cloud):

$\mathrm{LWP}_{\mathrm{WH} 06}=\frac{5}{9} \tau r_{\mathrm{eff}}$

We used both formulae to compare SSFR and SWS LWP retrievals to those by microwave radiometers.

\section{Retrieval results}

\subsection{Case selection}

The plane-parallel radiative transfer model and Mie theory applied in this study restricts our analysis to homogeneous liquid water clouds. Two filters were applied to exclude ice clouds and inhomogeneous scenes: (1) a phase detection flag ice or mixed-phase clouds and (2) an irradiance-based criterion for heterogeneous scene detection. Differences between liquid water and ice spectral absorption provide a simple discriminator of the thermodynamic phase in clouds. Pilewskie and Twomey (1987) and Ehrlich et al. (2008) used the spectral slope to retrieve cloud phase information from reflectance observations. A similar approach was used in this study to remove cases dominated by ice. Figure 8 shows the bulk absorption coefficient $\left(k_{\mathrm{b}}\right)$ for liquid water and ice, over the spectral region between $1667-1695 \mathrm{~nm}$. The coalbedo $\left(1-\varpi_{0}\right)$ is linearly proportional to $k_{\mathrm{b}}$ and the effective radius in the geometric optics, weak absorption limit (Twomey and Bohren, 1980). Model calculations at a $\mu_{0}=0.75$ show that the spectral slope of the transmitted radiance is negative for values of optical thickness from 1 to 100 and for effective radii ranging from $1 \mu \mathrm{m}$ to $30 \mu \mathrm{m}$. The negative slope in $k_{\mathrm{b}}$ for ice results in a positive slope in the transmitted radiance across this wavelength region. Transmittance observations with a positive slope were therefore flagged as ice or mixedphase and excluded from further analysis. 


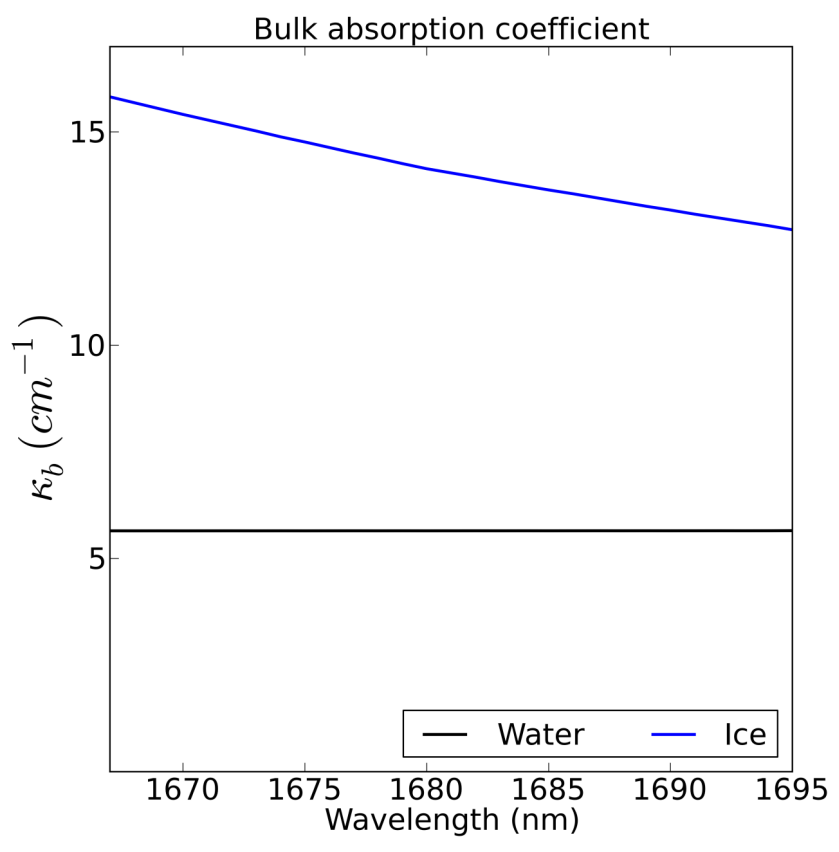

Fig. 8. The bulk absorption coefficient for liquid water and ice calculated from the refractive indices taken from Warren (1984).

To avoid highly inhomogeneous scenes, we examined the temporal behavior of the measured transmitted irradiance. Because irradiance encompasses the entire hemisphere above the instrument, it depends on the scene well outside the tightly restricted angular region of the radiance measurement. The transmitted irradiance time series from a homogeneous cloud is relatively constant, in contrast to that from a broken cloud field which exhibits sudden changes (Dutton et al., 2004). Irradiance time series were examined to identify such cases. The irradiance was provided by SSFR during ICEALOT and by the MFRSR at the SGP site. Figure 9 shows the irradiance time series for the cases used in this study. Figure 9a shows the MFRSR irradiance at the SGP site on 10 April 2007 over the time period from 17.0 to 19.0 UTC. Figure $9 \mathrm{~b}$ shows the same time period on 12 April 2007; due to cloud inhomogeneities, the time period from 17.5 to 17.8 UTC and 18.4 to 19.0 UTC were excluded from the analysis. The data from the SGP were from different days that were close enough in time for the surface albedo conditions and solar zenith angles to be similar. Figure $9 \mathrm{c}$ shows SSFR measurements from ICEALOT for a one-hour period on 20 March 2008. The data from 16-17 UTC was selected for analysis. During this time, the Knorr was passing through Long Island Sound.

The results are presented as comparisons between (1) the standard retrieval applied to transmittance (dual-wavelength method) and the standard retrieval (dual-wavelength method) and the spectral retrieval (transmittance-slope method) applied to transmittance, (2) the retrieval uncertainties of the aforementioned algorithms, (3) retrieved optical thickness

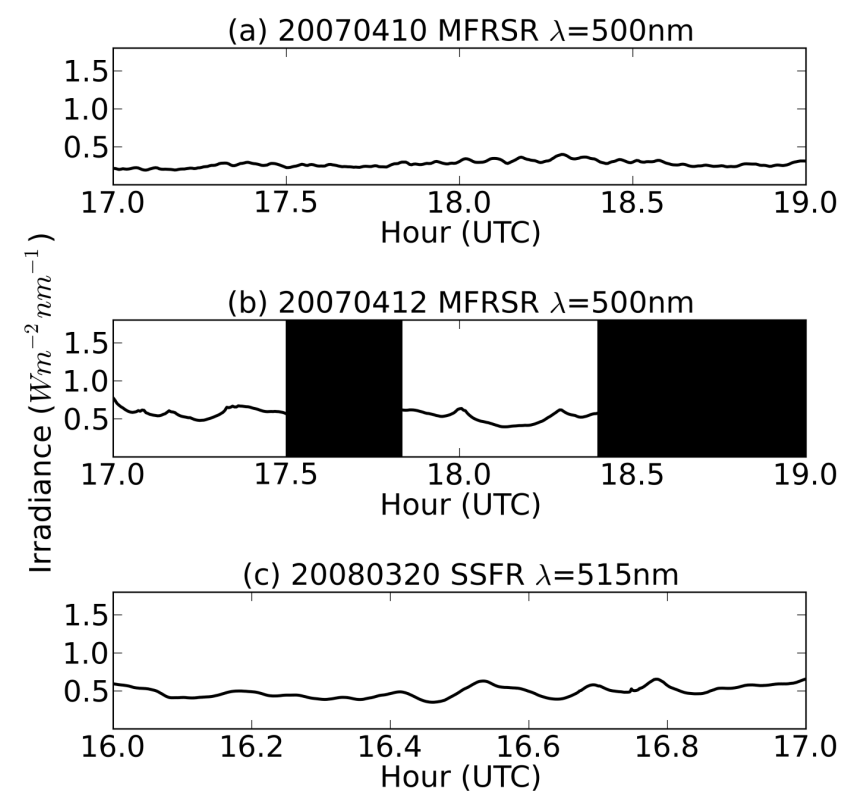

Fig. 9. Time series observations of irradiance from the MFRSR (a and b) and the SSFR (c). The black boxes in part (b) cover time periods excluded from this analysis.

and effective radius from the SWS and MODIS and (4) liquid water path retrieved from the MWR, MODIS, and the SWS. The SWS LWP was calculated using Eqs. (8) and (9). No MODIS overpass was available during the time period chosen from ICEALOT.

The retrieval quality from these cases was assessed in terms of the effective radius retrieval uncertainty. Retrievals that resulted in an effective radius uncertainty of less than $2 \mu \mathrm{m}$ were considered valid; outside of that range, the retrieval was flagged as invalid. For an effective radius between $5 \mu \mathrm{m}$ and $20 \mu \mathrm{m}$, this absolute uncertainty threshold corresponds to a relative uncertainty between $40 \%$ and $10 \%$.

\subsection{Optical thickness and effective radius retrievals}

Figures 10 and 11 show the retrievals for the ICEALOT cases and the SGP cases, respectively. In a and c, the optical thickness and effective radius as retrieved by the new spectral method (x-axis) are directly compared with results from the standard method (y-axis). In (b) and (d), the associated histograms are shown for all data (solid lines) and data points with an effective radius absolute uncertainty below a threshold of $2 \mu \mathrm{m}$ (dashed lines). Although the scatter plots of optical thickness show good agreement between the methods for an optical thickness below 60 , the histograms reveal that in fact, standard retrievals are only valid for $\tau>25$ in the sense of the effective radius uncertainty threshold, whereas the new spectral method provides meaningful retrievals even for $\tau<25$. This is expected based on the optical thickness sensitivity analysis and the shape of the lookup table (Figs. 3b and 

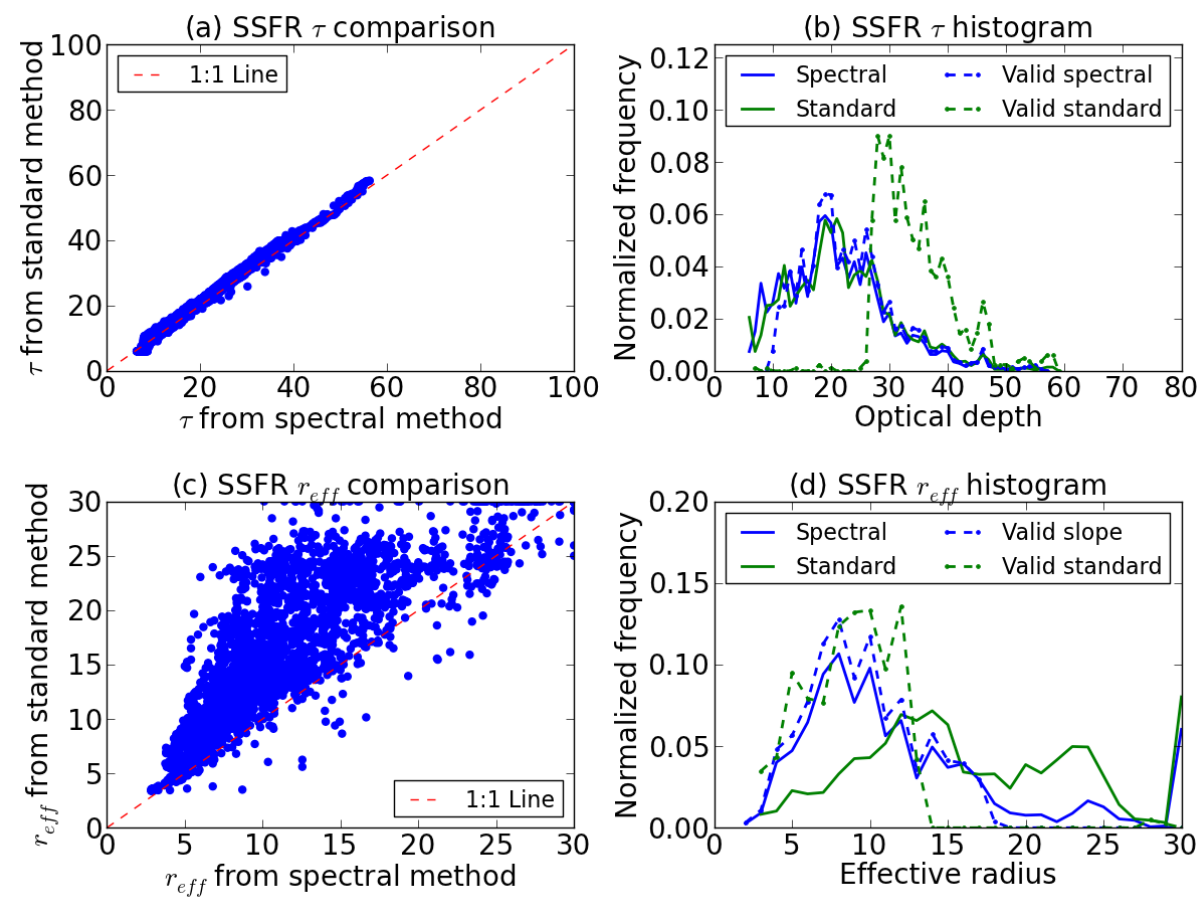

Fig. 10. Cloud parameter retrieval results comparing the spectral method to the standard retrieval method applied to SSFR data from ICEALOT. Shown are (a) scatter plot of the retrieved optical thickness for the two methods showing all retrievals (solid) and valid retrievals (dashed), (b) a histogram of the retrieved optical thickness for both methods, (c) scatter plot of the retrieved effective radius for the two methods, and (d) a histogram of the retrieved effective radii for both methods showing all retrievals (solid) and valid retrievals (dashed).
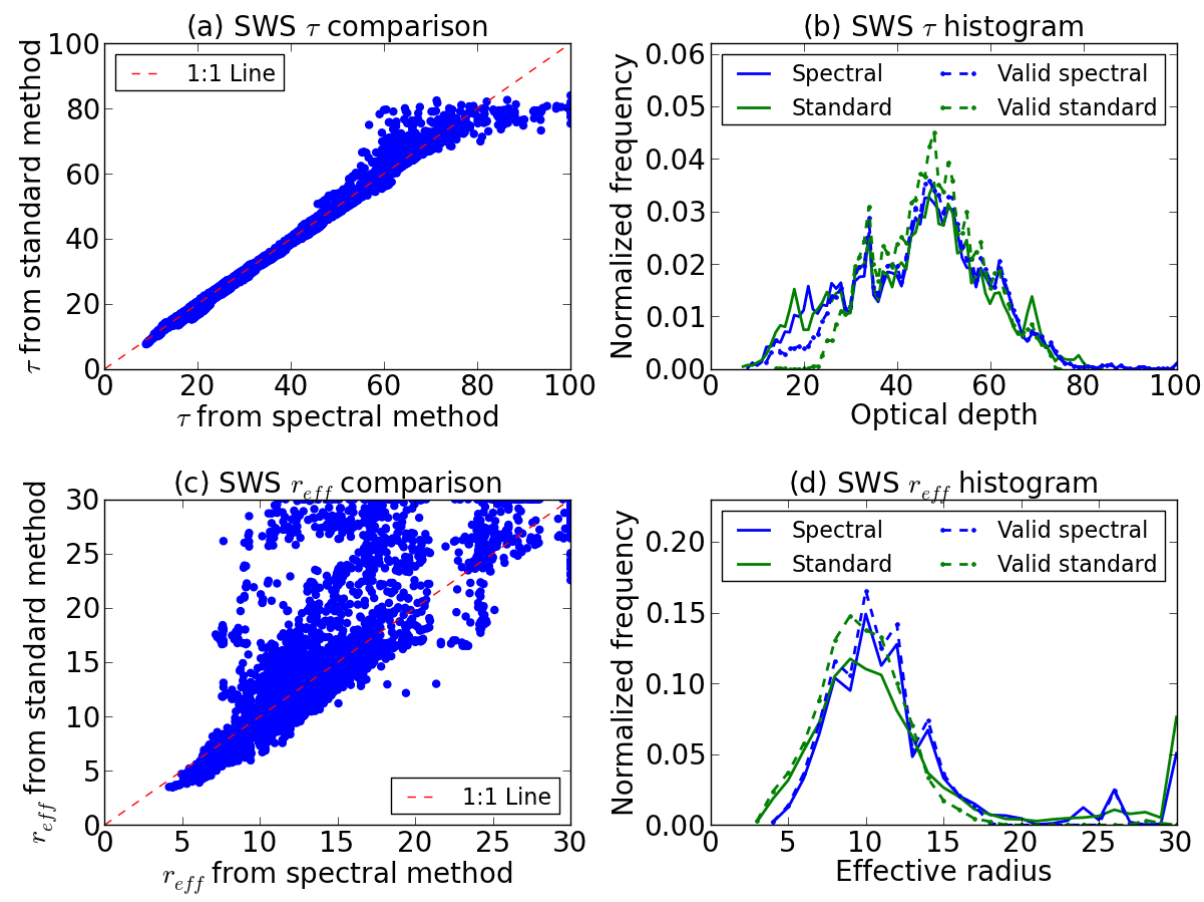

Fig. 11. Cloud parameter retrieval results comparing the spectral method to the standard retrieval method applied to SWS data from the SGP. Shown are (a) scatter plot of the retrieved optical thickness for the two methods showing all retrievals (solid) and valid retrievals (dashed), (b) a histogram of the retrieved optical thickness for both methods, (c) scatter plot of the retrieved effective radius for the two methods, and (d) a histogram of the retrieved effective radii for both methods showing all retrievals (solid) and valid retrievals (dashed). 
9). For the effective radius, the standard retrieval is biased towards larger values, when compared to the spectral method, especially for the ICEALOT case. The histogram showing all the data peaks around $8 \mu \mathrm{m}$ for the spectral method and around $14 \mu \mathrm{m}$ for the standard method. However, the histograms using only data with an effective radius uncertainty below $2 \mu \mathrm{m}$ (dashed lines) both peak around $9 \mu \mathrm{m}$ and have more similar shapes. For the ICEALOT cases, $84 \%$ of the spectral retrievals meet the threshold requirement and $24 \%$ for the standard retrieval. This demonstrates the lack of sensitivity of the standard method to effective radius for $\tau<25$. For the thicker clouds encountered at the SGP site, the most notable change in the histograms is for $\tau<25$. Overall, $90 \%$ of the spectral retrievals meet the threshold requirement and $78 \%$ for the standard retrieval. This means that for thicker clouds, the standard method is as sensitive to effective radius as the spectral method.

Both effective radius histograms show a peak at $30 \mu \mathrm{m}$ which is the largest value in the lookup tables. This peak would presumably spread out over larger values of effective radius if the lookup table were extended. The exact reason for the systematic overestimation of the effective radius by the standard method is so far unknown. A possible explanation is that in the forward calculations, constant effective radius and extinction are assumed throughout the cloud. A more physical vertical profile could lead to different effects in the standard retrieval and the spectral retrieval. Undetected ice crystals or horizontal inhomogeneities could be further causes for the discrepancies of the two retrievals. This will be examined in future research.

\subsection{Uncertainty comparisons}

Equations (6) and (7) were used to calculate the uncertainty in the retrieved optical thickness and effective radius for the standard and the spectral methods. They are shown in Fig. 12 (optical thickness) and Fig. 13 (effective radius). The spectral retrieval does not reduce the optical thickness uncertainty, which is around 3\% in both cases. This is consistent with the sensitivity analysis presented in Sect. 3.2, which does not predict large optical thickness accuracy differences between the methods. Figure 13 shows the effective radius absolute uncertainties, along with the $2 \mu \mathrm{m}$ threshold. For the thin clouds encountered during ICEALOT (Fig. 13a), the spectral method ( $84 \%$ valid retrievals) outperforms the standard retrieval ( $24 \%$ valid retrievals), whereas the uncertainties stay below the threshold for the thicker clouds from the SGP cases (Fig. 13b, 90\% valid retrievals for the spectral method and $78 \%$ for the standard method). While the different optical thickness ranges appear to be the primary reason for the different effective radius uncertainties, other sources, such as cloud phase or spatial heterogeneities, will be explored.

\subsection{Time series of retrieval results}

To explore the difference between the standard and the spectral method in more detail, Figs. 14 and 15 show time series of a small subset of the ICEALOT and SGP data. Figure 14 shows six minutes from ICEALOT on 20 March 2008. In addition to optical thickness (first panel) and effective radius (second panel), the LWP derived from Eqs. (8) and (9) is shown along with MWR retrievals (third and fourth panel). The shaded areas show the uncertainties. For the whole time period from 16.0 UTC to 17.0 UTC, the mean retrieved LWP was $100 \pm 20 \mathrm{~g} \mathrm{~m}^{-2}$ for the MWR and $155 \mathrm{~g} \mathrm{~m}^{-2}$ and $222 \mathrm{~g} \mathrm{~m}^{-2}$ for the spectral and standard methods, respectively, using the constant effective radius assumption (Eq. 8). From the WH06 assumption (Eq. 9), mean retrieved LWP of $129 \mathrm{~g} \mathrm{~m}^{-2}$ and $185 \mathrm{~g} \mathrm{~m}^{-2}$ for the spectral and standard methods were obtained. The SSFR retrievals were generally more variable than the MWR retrieved liquid water path. These differences could be the result of the different sampling volumes between sensors. The field of view of these instruments is $3^{\circ}$ for the SSFR and $5.7^{\circ}$ for the MWR. The integration time and sampling interval for SSFR is $20 \mathrm{~ms}$ and $1 \mathrm{~s}$, respectively, and $1 \mathrm{~s}$ and $16 \mathrm{~s}$ for MWR.

Figure 15 shows a time series of optical thickness, effective radius and LWP from the SGP site on 10 April 2007, similar to Fig. 14. The improved agreement between the standard and spectral retrievals is seen again when comparing Fig. 14 (ICEALOT, thinner cloud) and Fig. 15 (SGP, thicker cloud). The SGP MWR and SWS LWP retrievals were within the uncertainty of both methods throughout this time period assuming a WH06 cloud (Eq. 9). The mean retrieved LWP was $272 \pm 20 \mathrm{~g} \mathrm{~m}^{-2}$ for the MWR, $367 \mathrm{~g} \mathrm{~m}^{-2}\left(306 \mathrm{~g} \mathrm{~m}^{-2}\right)$ for the spectral method, and $336 \mathrm{~g} \mathrm{~m}^{-2}\left(280 \mathrm{~g} \mathrm{~m}^{-2}\right)$ for the standard methods, assuming constant effective radius (WH06 cloud).

Table 2 shows comparisons between cloud retrievals from SWS and two MODIS overpasses of the SGP site on 10 April 2007. The LWP, derived from the SWS retrievals (Eq. 9), is also compared to the LWP retrievals of MODIS and the MWR. The MODIS Aqua overpass occurred at 18.86 UTC, and the MODIS $1 \mathrm{~km}$ pixel was centered approximately $100 \mathrm{~m}$ away from SWS. MODIS retrieved optical thickness within 7 of the SWS retrieved optical thickness, within the MODIS and SWS uncertainties. The Terra overpass occurred at 17.21 UTC, and SWS was located towards the edge of the pixel. In this case, MODIS and SWS optical thickness differed by about 20, exceeding the uncertainty of the respective retrievals. The MODIS effective radius was within the uncertainty of the spectral method, but outside the uncertainty of the standard method. For the Terra overpass, the retrieved optical thickness of the adjacent MODIS pixels ranged from 31 to 38 , which suggests cloud inhomogeneities as a possible explanation for the discrepancies between MODIS and SWS. 


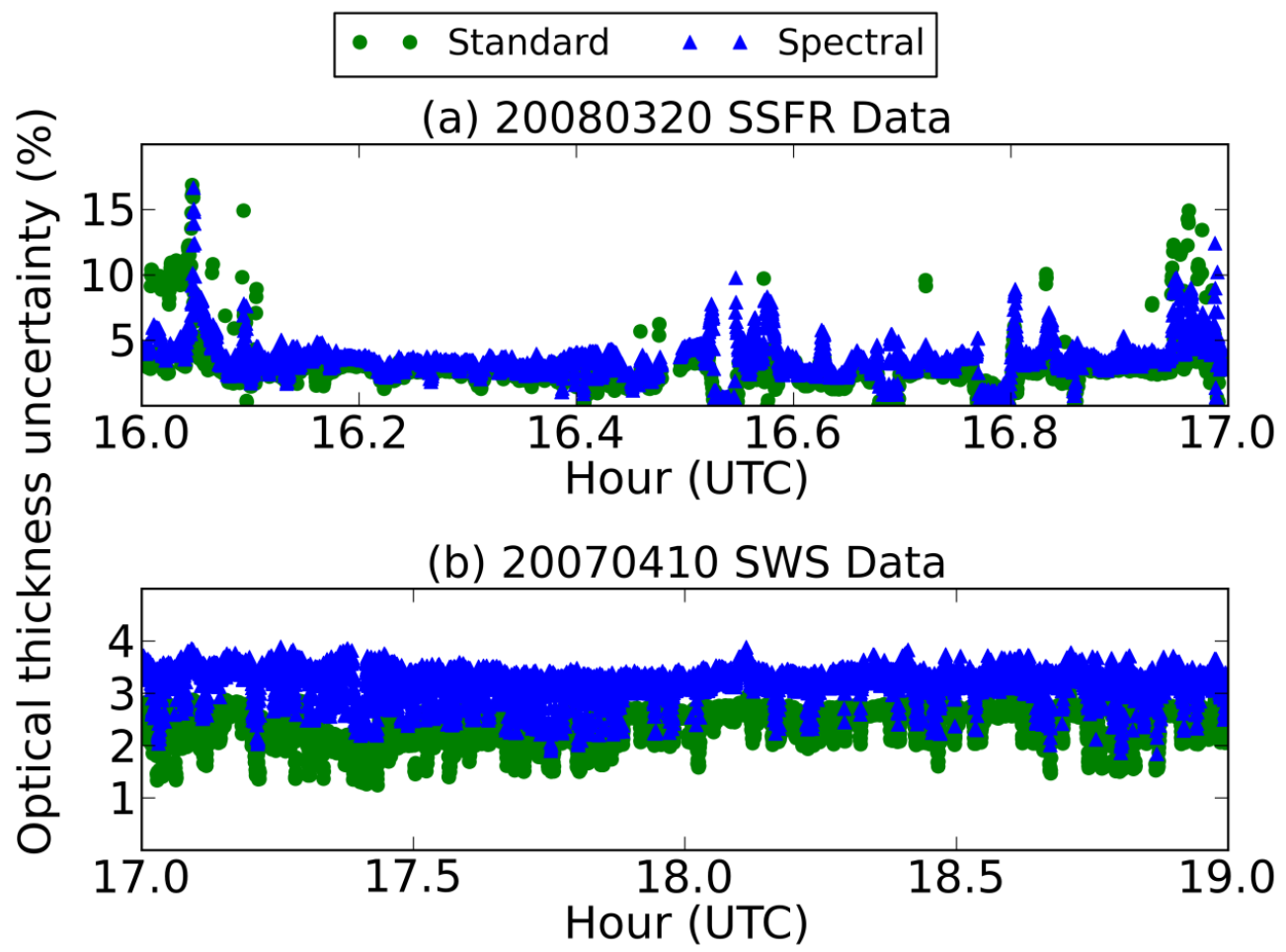

Fig. 12. Time series plot of the relative optical thickness uncertainty for the (a) ICEALOT case on 20 March 2008 and (b) the ARM case on 10 April 2007.

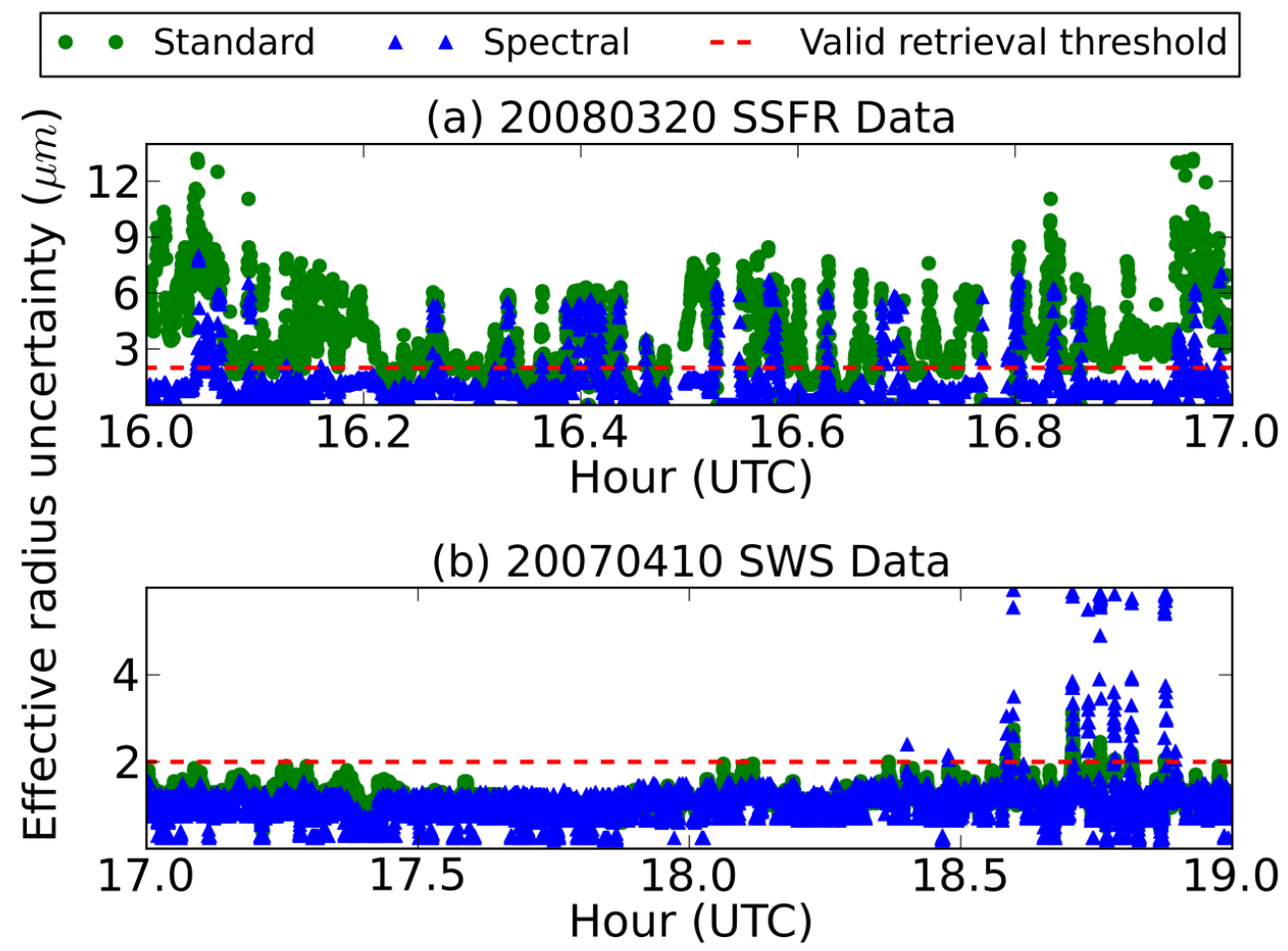

Fig. 13. Time series plots of the effective radius uncertainty calculations for the (a) ICEALOT case on 20 March 2008 and (b) the ARM case on 10 April 2007. The red dashed line shows the $2 \mu \mathrm{m}$ uncertainty level which for this work was defined as the threshold of a valid retrieval. 


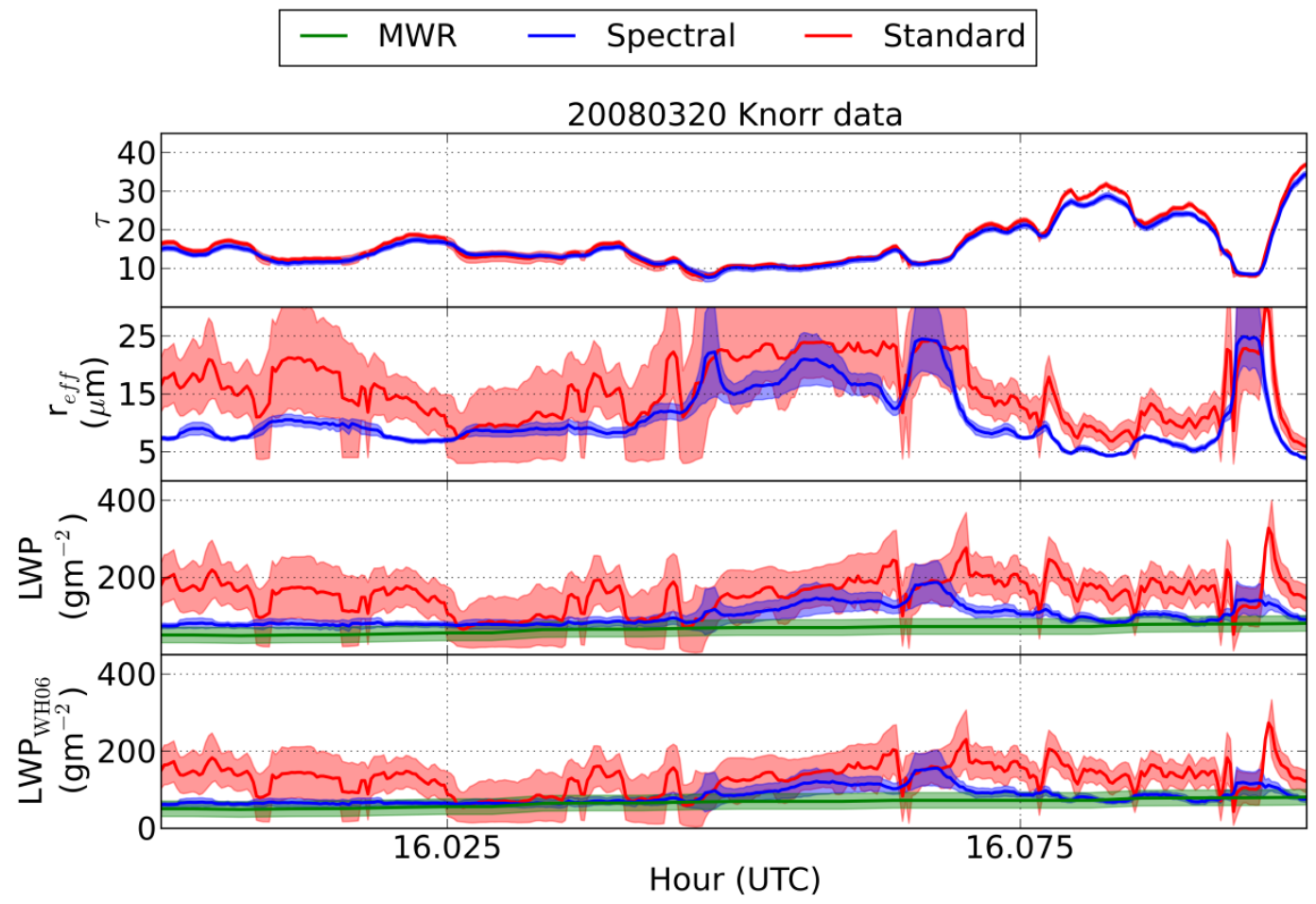

Fig. 14. Time series plots of SSFR retrievals of optical thickness and effective radius. LWP retrievals from the NOAA MWR along with calculated LWP from SSFR retrievals. The shaded regions show the estimated uncertainty.

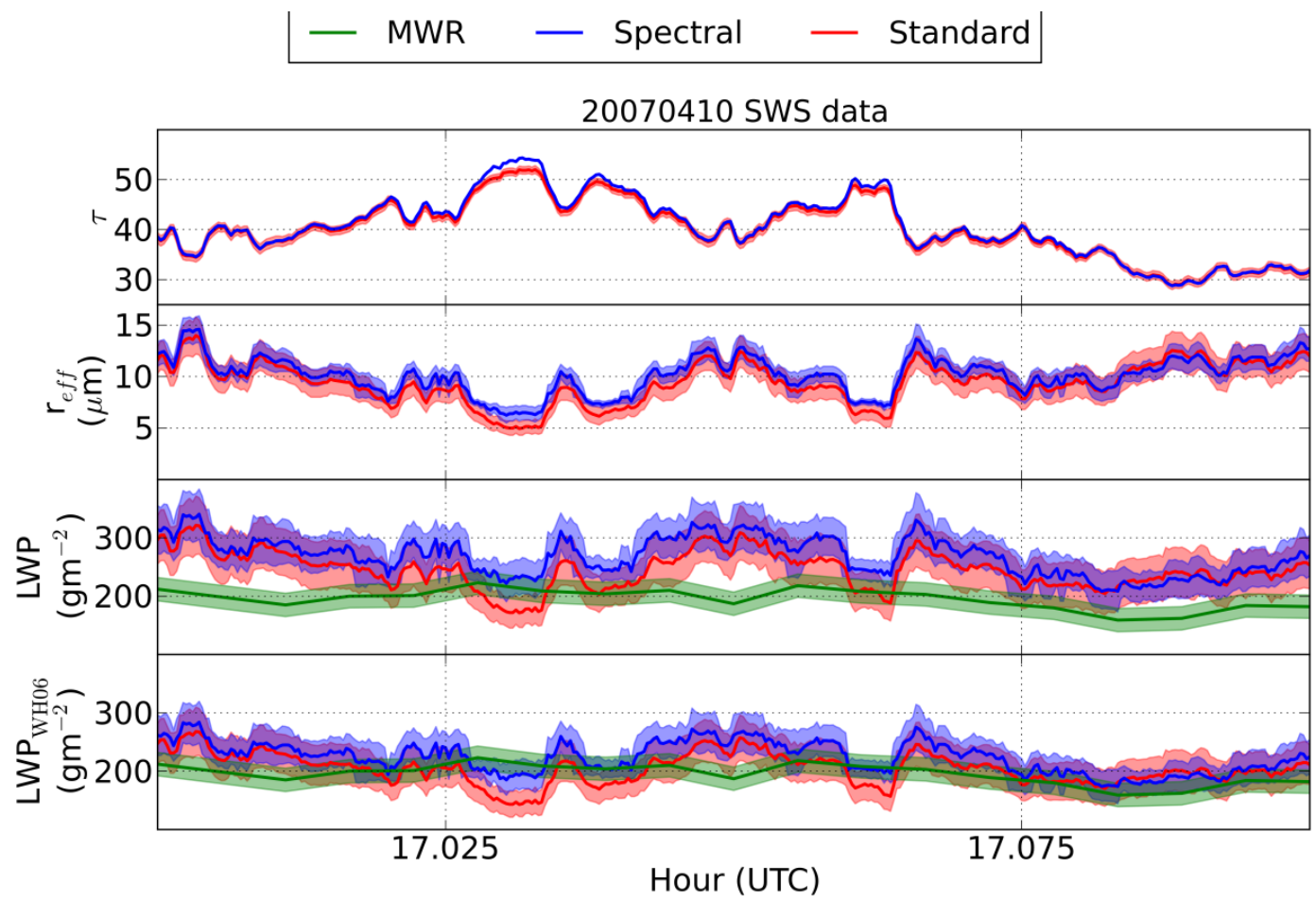

Fig. 15. Time series plots of SWS retrievals of optical thickness and effective radius. LWP retrievals from the ARM MWR along with calculated LWP from SWS retrievals. The shaded regions show the estimated uncertainty. 
Table 2. The spectral retrievals presented with coincident MODIS AQUA (top) and TERRA (bottom) overpasses of the ARM Southern Great Plains facility on 10 April 2007.

\begin{tabular}{|c|c|c|c|c|}
\hline 18.86 UTC & Spectral & Standard & $\begin{array}{r}\text { MODIS AQUA } \\
(2.1 \mu \mathrm{m} \text { retrieval })\end{array}$ & MWR \\
\hline Optical thickness & $52.6 \pm 1.8$ & $52.3 \pm 1.4$ & $45.6 \pm 12.27$ & \\
\hline Effective radius $(\mu \mathrm{m})$ & $13.6 \pm 1.4$ & $12.8 \pm 1.3$ & $13.3 \pm 0.93$ & \\
\hline Liquid water path $\left(\mathrm{gm}^{-2}\right)$ & $396.0 \pm 55.9$ & $371.9 \pm 47.7$ & $388 \pm 169.2$ & $319.0 \pm 20$ \\
\hline 17.21 UTC & & & $\begin{array}{l}\text { MODIS TERRA } \\
(2.1 \mu \mathrm{m} \text { retrieval })\end{array}$ & \\
\hline Optical thickness & $47.2 \pm 1.6$ & $45.9 \pm 1.6$ & $31.3 \pm 5.3$ & \\
\hline Effective radius $(\mu \mathrm{m})$ & $10.5 \pm 0.7$ & $8.6 \pm 1.1$ & $11.37 \pm 0.8$ & \\
\hline Liquid water path $\left(\mathrm{gm}^{-2}\right)$ & $275 \pm 28.0$ & $219.3 \pm 32.8$ & $227 \pm 64.9$ & $233.0 \pm 20$ \\
\hline
\end{tabular}

\section{Conclusions}

A new spectral algorithm for the retrieval of cloud optical thickness and cloud particle effective radius from cloud transmittance was introduced. This was necessary because the dual-wavelength approach, which is used in standard reflectance-based retrievals, is not adequate for cloud transmittance. In particular, the effective radius retrievals are associated with large uncertainties, especially for optically thin clouds $(\tau<25)$. The new algorithm uses the continuous spectrum measured by the SSFR and SWS instruments. It exploits the spectral shape of cloud transmittance in the near-infrared wavelength range to increase the sensitivity to the effective radius even for thin clouds. The higher sensitivity is achieved by using the transmittance at $515 \mathrm{~nm}$ and the spectral slope of transmittance from $1565 \mathrm{~nm}$ to $1634 \mathrm{~nm}$. Normalizing the near-infrared transmittance by its value at $1565 \mathrm{~nm}$ before calculating the spectral slope reduces the dependence of the retrieval on spectrally correlated errors, such as radiometric uncertainty.

To compare the retrieval accuracy for the standard (dualwavelength) method with that of the new spectral method, the instrument uncertainties were propagated through both algorithms. The standard and spectral retrievals were applied to selected field data from the ARM SGP facility and from ICEALOT. For the thicker cloud cases encountered at the SGP site, the average retrieved effective radius and optical thickness from the two retrieval methods were virtually identical whereas for the thinner clouds from ICEALOT, the standard method retrieved considerably higher effective radius values that were associated with large uncertainties. When defining $2 \mu \mathrm{m}$ as the upper uncertainty threshold for an effective radius retrieval to be regarded as meaningful, the standard method failed to provide valid retrievals for thin clouds $(\tau<25)$, whereas the spectral method provided retrievals for the entire optical thickness range. For the ICEALOT case, the application of the spectral method resulted in nearly 3.5 times the number of valid retrievals when compared to the standard method.

From the retrieved optical thickness and effective radius, liquid water path was derived, assuming vertically constant effective radius, and increasing effective radius above cloud base. A comparison of the derived LWP with the observations from MWR favors the assumption of vertically increasing effective radius (agreement between SSFR/SWSderived and MWR values within $20 \%$, as opposed to $55 \%$ when assuming vertical homogeneity). Explaining the differences on the basis of sensor sampling volumes and cloud inhomogeneities will require additional work and is under investigation.

Retrievals from two MODIS overpasses over the SGP site were also compared to the SWS retrievals. The MODIS pixels surrounding the site showed a more homogeneous cloud scene for the Aqua overpass on 10 April 2007 than for the Terra overpass. The disagreement of SWS and MODIS retrievals for the latter case were therefore attributed to horizontal cloud inhomogeneities.

This publication serves as first introduction and assessment of the new spectral approach. More systematic studies are needed to understand the differences between standard and spectral retrieval, and satellite and microwave observations under varying cloud conditions. In particular, model errors related to undetected ice crystals, the vertical cloud profile (including multi-layer conditions), horizontal cloud inhomogeneities, and the spectral shape of surface albedo need to be further analyzed. Preliminary calculations showed that when replacing a spectrally constant with a spectrally increasing surface albedo (red vs. dotted line in Fig. 1) in the forward calculations, the retrieved effective radius changed by up to $11 \%$. 
Improvements of the algorithm could be expected from using spectral slopes not only around $1.6 \mu \mathrm{m}$, but also in other wavelength regions, which could further decrease the dependence on spectrally correlated errors. It is also possible to use the spectral shape directly, without going through a linear regression of the data that is used to obtain the slope. Since the actual shape deviates from the linear behavior, this may reduce the model contribution to the total retrieval error. The error analysis presented in this paper is only preliminary. A more thorough probabilistic assessment based on optimal estimation theory and a method by Vukicevic et al. (2010) will be undertaken. In this way, the contributions of correlated, uncorrelated, and model error components can be clearly separated, the information content can be obtained, and the retrieval error can be placed on a sounder footing.

Acknowledgements. This work was supported under NASA grant NNX08AI83G and NOAA grant NA06OAR4310085. The manuscript has gained tremendously from the reviewer's suggestions, which also encouraged the authors to improve the retrieval in the near future. We thank Warren Gore and Antony Trias from NASA Ames for their continued and reliable support of the SSFR during field missions. The SWS was built at NASA Ames for the SGP ARM site.

Edited by: G. Feingold

\section{References}

Barker, H. W. and Marshak, A.: Inferring optical depth of broken clouds above green vegetation using surface solar radiometric measurements, J. Atmos. Sci., 58, 2989-3006, 2001.

Bergstrom, R. W., Pilewskie, P., Schmid, B., and Russell, P. B.: Estimates of the spectral aerosol single scattering albedo and aerosol radiative effects during SAFARI 2000, J. Geophys. Res., 108, 8474, doi:10.1029/2002JD002435, 2003.

Chiu, J. C., Huang, C., Marshak, A., Slutsker, I., Giles, D. M., Holben, B. N., Knyazikhin, Y., and Wiscombe, W. J.: Cloud optical depth retrievals from the Aerosol Robotic Network (AERONET) cloud mode observations, J. Geophys. Res., 115, D14202, doi:10.1029/2009JD013121, 2010.

Chýlek, P. and Ramaswamy, V.: Simple approximation for infrared emissivity of water clouds, J. Atmos. Sci., 39, 171-177, 1982.

Clark, R. N., Swayze, G. A., Wise, R., Livo, E., Hoefen, T., Kokaly, R., and Sutley, S. J.: USGS digital spectral library splib06a: US Geological Survey, Digital Data Series 231, 2007.

Coddington, O. M., Schmidt, K. S., Pilewskie, P., Gore, W. J., Bergstrom, R. W., Román, M., Redemann, J., Russell, P. B., Liu, J., and Schaaf, C. C.: Aircraft measurements of spectral surface albedo and its consistency with ground-based and space-borne observations, J. Geophys. Res.-Atmos., 113, doi:10.1029/2008JD010089, 2008.

Dutton, E. G., Farhadi, A., Stone, R. S., Long, C. N., and Nelson, D. W.: Long-term variations in the occurrence and effective solar transmission of clouds as determined from surface-based total irradiance observations, J. Geophys. Res.- Atmos., 109, D03204, doi:10.1029/2003JD003568, 2004.
Ehrlich, A., Bierwirth, E., Wendisch, M., Gayet, J.-F., Mioche, G., Lampert, A., and Heintzenberg, J.: Cloud phase identification of Arctic boundary-layer clouds from airborne spectral reflection measurements: test of three approaches, Atmos. Chem. Phys., 8, 7493-7505, doi:10.5194/acp-8-7493-2008, 2008.

Evans, F. K.: The spherical harmonic discrete ordinate method for three-dimensional atmospheric radiative transfer, J. Atmos. Sci., 55, 429-446, 1998.

Forster, P., Ramaswamy, V., Artaxo, P., Berntsen, T., Betts, R., Fahey, D. W., Haywood, J., Lean, J., Lowe, D. C., Myhre, G., Nganga, J., Prinn, R., Raga, G., Schulz, M., and Van Dorland, R.: Changes in Atmospheric Constituents and in Radiative Forcing, in: Climate Change 2007: The Physical Science Basis. Contribution of Working Group I to the Fourth Assessment Report of the Intergovernmental Panel on Climate Change, edited by: Solomon, S., Qin, D., Manning, M., Chen, Z., Marquis, M., Averyt, K. B., Tignor, M., and Miller, H. L., Cambridge University Press, Cambridge, United Kingdom and New York, NY, USA, 131-217, 2007.

Hansen, J. E. and Hovenier, J. W.: Interpretation of the polarization of Venus, J. Atmos. Sci., 31, 1137-1160, 1974.

Hansen, J. E. and Pollack, J. B.: Near-infrared light scattering by terrestrial clouds, J. Atmos. Sci., 27, 265-281, 1970.

Harrison, L., Michalsky, J., and Berndt, J.: Automated multifilter rotating shadow-band radiometer: an instrument for optical depth and radiation measurements, Appl. Optics, 33, 5118-5125, 1994.

Holben, B.: AERONET: A federated instrument network and data archive for aerosol characterization, Remote Sens. Environ., 66, 1-16, 1998.

Kikuchi, N., Nakajima, T., Kumagai, H., Kuroiwa, H., Kamei, A., Nakamura, R., and Nakajima, T. Y.: Cloud optical thickness and effective particle radius derived from transmitted solar radiation measurements: Comparison with cloud radar observations, J. Geophys. Res., 111, D07205, doi:10.1029/2005JD006363, 2006.

King, M. D., Menzel, P. W., Grant, P. S., Myers, J. S., Arnold, T. G., Platnick, S. E., Gumley, L. E., Tsay, S., Moeller, C. C., Fitzgerald, M., Brown, K. S., and Osterwisch, F. G.: Airborne Scanning Spectrometer for remote sensing of cloud, aerosol, water vapor, and surface properties, J. Atmos. Ocean. Tech., 13, 777794, 1996.

Leontyeva, E. and Stamnes, K.: Estimations of cloud optical thickness from ground-based measurements of incoming solar radiation in the Arctic, J. Climate, 7, 566-578, 1994.

Liljegren, J. C. and Lesht, B. M.: Measurements of integrated water vapor and cloud liquid water from microwave radiometers at the DOE ARM Cloud and Radiation Testbed in the US Southern Great Plains., in: IEEE International Geosciences and Remote Sensing Symposium (IGARSS), Lincoln, NE, 21-26 May, 1996, 1675-1677, 1996.

Marshak, A., Knyazikhin, Y., Evans, K. D., and Wiscombe, W. J.: The RED versus NIR plane to retrieve broken-cloud optical depth from ground-based measurements, J. Atmos. Sci., 61, 1911-1925, 2004.

Nakajima, T. and King, M. D.: Determination of the optical thickness and effective particle radius of clouds from reflected solar radiation measurements. Part I: Theory, J. Atmos. Sci., 47, 1878 1893, 1990.

Pilewskie, P. and Twomey, S.: Cloud phase discrimination by re- 
flectance measurements near 1.6 and $2.2 \mu \mathrm{m}$, J. Atmos. Sci., 44, 3419-3420, 1987.

Pilewskie, P., Pommier, J., Bergstrom, R., Gore, W., Howard, S., Rabbette, M., Schmid, B., Hobbs, P. V. and Tsay, S. C.: Solar spectral radiative forcing during the Southern African Regional Science Initiative, J. Geophys. Res., 108, 8486, doi:10.1029/2002JD002411, 2003.

Platnick, S.: Vertical photon transport in cloud remote sensing problems, J. Geophys. Res., 105, 22919-22935, 2000.

Platnick, S., King, M. D., Ackerman, S. A., Menzel, W. P., Baum, B. A., Riédi, J. C., and Frey, R. A.: The MODIS Cloud Products: Algorithms and Examples From Terra, IEEE T. Geosci. Remote, 41, 459-473, 2003.

Rawlins, F. and Foot, J. S.: Remotely Sensed Measurements of Stratocumulus Properties during FIRE Using the C130 Aircraft Multi-channel Radiometer, J. Atmos. Sci., 47, 2488-2504, 1990.

Schiffer, R. A. and Rossow, W. B.: The International Satellite Cloud Climatology Project (ISCCP): The First Project of the World Climate Research Programme., B. Am. Meteorol. Soc., 64, 779784, 1983.

Stokes, G. M. and Schwartz, S. E.: The Atmospheric Radiation Measurement (ARM) Program: Programmatic Background and Design of the Cloud and Radiation Test Bed, B. Am. Meteorol. Soc., 75, 201-1222, 1994.

Taylor, J. R.: An Introduction to Error Analysis: The study of uncertainties in physical measurements, 2nd, Sausalito, California, University Science Books, 1996.
Turner, D. D., Vogelmann, A. M., Austin, R. T., Barnard, J. C., Cady-Pereira, K., Chiu, J. C., Clough, S. A., Flynn, C., Khaiyer, M. M., Liljegren, J., Johnson, K., Lin, B., Long, C., Marshak, A., Matrosov, S. Y., McFarlane, S. A., Miler, M., Min, Q., Minnis, P., O'Hirok, W., Wang, Z., and Iscombe, W.: Thin liquid water clouds: Their importance and our challenge, B. Am. Meteorol. Soc., 88, 177-190, 2007.

Twomey, S. and Bohren, C. F.: Simple approximations for calculations of absorption in clouds, J. Atmos. Sci., 37, 2086-2095, 1980.

Twomey, S. and Cocks, T.: Remote sensing of cloud parameters from spectral reflectance in the near-infrared, Beitr. Phys. Atmos., 62, 172-179, 1989.

Vukicevic, T., Coddington, O,. and Pilewskie, P.: Characterizing the retrieval of cloud properties from optical remote sensing, J. Geophys. Res., 115, D20211, doi:10.1029/2009JD012830, 2010.

Warren, S. G.: Optical Constants of Ice from the Ultraviolet optical thickness the Microwave, Appl. Optics, 23, 1206-1225, 1984.

Westwater, E. R.: Ground-Based microwave remote sensing of meteorological variables, atmospheric remote sensing by microwave radiometry, Janssen, M. A., Wiley, New York, NY, 145207, 1993.

Westwater, E. R., Han, Y., Shupe, M. D., and Matrosov, S. Y.: Analysis of integrated cloud liquid and precipitable water vapor retrievals from microwave radiometers during the Surface Heat Budget of the Arctic Ocean project, J. Geophys. Res., 106, 32019-32030, 2001.

Wood, R. and Hartmann, D. L.: Spatial variability of liquid water path in marine low cloud: The importance of mesoscale cellular convection, J. Climate, 19, 1748-1764, 2006. 